\title{
Brandenburg-Preußen und Sachsen in der Frühen Neuzeit im Vergleich
}

\author{
von \\ DETLEF DÖRING
}

\section{Barthold Georg Niebubr und sein Buch über „Preußens Recht gegen den sächsischen Hof“}

$\mathrm{Zu}$ den schwierigsten und verwickeltsten Fragen, die auf dem Wiener Kongress 1814/15 zur Verhandlung anstanden, gehörte die nach dem weiteren Schicksal des besiegten Königreiches Sachsen. Dessen Herrscher war seit der Völkerschlacht bei Leipzig ein Gefangener des Königs von Preußen, der mit Vehemenz die Inkorporation des gesamten, seit Herbst 1813 besetzten sächsischen Staatsgebietes in die preußischen Lande forderte. Die entsprechenden Verhandlungen der Diplomaten wurden durch einen regen Schriftenkrieg begleitet, der das Für und Wider dieses Verlangens traktierte. Unter diesen Texten ragt, schon durch den Namen seines Autors, die Abhandlung „Preußens Recht gegen den sächsischen Hof“ hervor, verfasst von dem großen, als Begründer der modernen Geschichtsschreibung geltenden Historiker Barthold Georg Niebuhr. Auf einhundert Seiten in der Originalfassung bietet diese Schrift wenigstens im Kern die wesentlichen Argumente gegen Sachsen bzw. zugunsten Preußens, die seitdem in allen borussisch eingefärbten Erörterungen vorgetragen wurden, die sich mit dem gegenseitigen Verhältnis dieser beiden deutschen Länder beschäftigten.

„Kein deutsches Fürstenhaus“, lautet die mit einigem Pathos vorgetragene Feststellung des preußischen Hofhistoriografen, „hat sich in den traurigen Zeiten der Zerrüttung und der Ohnmacht Deutschlands, vom Westfälischen Frieden bis zum Tode Kaiser Karls VI., so durch Treue für die allgemeine deutsche Sache gegen den Einfluss und die Eroberungspläne der Fremden, durch Unverführbarkeit und kriegerische Dienste ausgezeichnet wie Brandenburg."1 Diese geradezu apodiktische Aussage wird in der weiteren Argumentation näher begründet und zwar im Kontrast zur ganz anders orientierten Politik Sachsens, wobei es zu einer grundsätzlichen Gegenüberstellung beider Staatswesen kommt. Das Urteil fällt, wie nicht anders zu erwarten, ganz und gar zuungunsten des südlichen Nachbarn aus: Während Preußen ständig und stets auf der Wacht gestanden habe, wenn Deutschlands Grenzen bedroht waren, hätte die „eitle Königssucht der sächsi-

1 Barthold Georg Niebuhr, Preußens Recht gegen den sächsischen Hof, in: Ders.,

Politische Schriften, in Auswahl hrsg. von Georg Küntzel, Frankfurt a. M. 1923

[Erstveröffentlichung 1814], S. 1-64, hier S. 37. 
schen Kurfürsten “ immer wieder fremde Truppen ins Reich gerufen, mit den dann sattsam bekannten schlimmen Folgen. ${ }^{2}$ Überhaupt beruhe das sächsische Länderkonglomerat, dessen Übergang in den preußischen Besitz Niebuhr so nachdrücklich fordert, auf reichlich dubiosen Grundlagen. Als Beispiel wird der Erwerb der Markgraftümer Ober- und Niederlausitz im Dreißigjährigen Krieg angeführt, der auf den Verrat der Sachsen an der protestantischen Sache zurückgehe. Preußens Territorialbesitz dagegen sei in jeder Hinsicht legitimiert. Das gilt auch und gerade für Schlesien, wie der an dieser Stelle vielleicht zur Skepsis neigende Leser umgehend unterrichtet wird. Friedrich II. habe, wie jeder „aufrichtige Deutsche“ sofort erkennen kann und muss, dieses Land unter „Gottes Führung“ erobert, u. a. als Befreier der dort lebenden unterdrückten Protestanten. Legitimer und illegitimer Ländererwerb stehen hier in einem scharfen, freilich reichlich nebulös begründeten Kontrast gegenüber.

Die Gegensätze zwischen beiden Staaten sind jedoch noch tiefer verwurzelt. „Preußen ist kein abgeschlossenes Land“, heißt es weiter, „es ist das gemeinsame Vaterland eines jeden Deutschen, der sich in Wissenschaften, in den Waffen, in der Verwaltung auszeichnet [...]. Mögen aber die Sachsen selbst erwägen, ob nicht ihr Staat in dieser Hinsicht grade das Gegenteil von Preußen war; in der Verwaltung, im Heer, in ihren gelehrten Anstalten?"3 Der sächsische Hof, so wird zur näheren Begründung angeführt, sei „durchaus undeutsch“ und die ständische Verfassung des Landes ganz und gar leblos. Dagegen hebe sich der Preuße ab als „Bürger eines freien Staates", denn im Kontrast zur aristokratisch bestimmten Ständegesellschaft in Sachsen gäbe es in Preußen keine Standesschranken, jeder "Jüngling“ könne Stammvater eines neuen Adelsgeschlechtes werden. ${ }^{4}$ Wissenschaft und Gelehrsamkeit schließlich träfen bei der sächsischen Regierung nur auf „Kargheit und Kälte“, wieder im grellen Gegensatz zu Preußen, das z. B. in einer Situation der tiefsten Bedrückung, also während der napoleonischen Herrschaft, dennoch die Kraft gefunden habe, die Universität Berlin zu gründen. Gelangten jetzt die sächsischen Bildungseinrichtungen unter preußische Herrschaft, würden sie „mit ganz anderem Geist" betrieben werden und u. a. eine opulente finanzielle Förderung erfahren, z. B. indem ihnen die Gelder zugeteilt würden, die bisher an die Sängerinnen und Kastraten der Dresdner Oper verschwendet worden wären. ${ }^{5}$

Manches von dem Gesagten mag dem Wunschdenken Niebuhrs aus der unmittelbaren Zeit nach Beendigung des Befreiungskrieges entsprungen sein, so die Behauptung von der Durchlässigkeit der sozialen Schichtung in Preußen. ${ }^{6}$ Den-

2 Ebd., S. 38.

3 Ebd., S. 51.

4 Zur Korrektur sei angemerkt, dass in der preußischen Armee außerhalb der Artillerie für einen Bürgerlichen kaum die Möglichkeit bestand, in den Offiziersrang aufzusteigen, was dagegen in der sächsischen Armee durchaus erreichbar war. Vgl. den Literaturhinweis in Anm. 49.

5 Niebuhr, Preußens Recht (wie Anm. 1), S. 52 f.

6 Ansätze zu einer solchen Vorstellungswelt lassen sich allerdings schon bis in die Zeit des Siebenjährigen Krieges zurückverfolgen. So will der Frankfurter Professor Thomas 
noch besitzen seine Kernbehauptungen eine Bedeutung jenseits von Tag und Stunde: Preußens deutsche Sendung, seine Rolle als Schutzmacht des Protestantismus, seine vorbildliche militärische Stärke, seine moderne und daher überlegene innere Verfassungsstruktur, seine Stellung als Vormacht auf dem Gebiet der Bildung und der Wissenschaften - sie alle begründen in der Publizistik fortan Preußens Anspruch auf eine führende Position innerhalb so ziemlich aller Lebensgebiete und das nicht nur in der Gegenwart, sondern auch im Rückblick auf die vergangenen Jahrhunderte. Sachsen dagegen erweist sich in allen aufgeführten Punkten als das erklärte Gegenteil: Eigensüchtiges Verhalten statt einer Vertretung der großen nationalen Interessen, Verrat am Protestantismus, Schwäche im Militärwesen, lähmender Modernisierungsrückstand in Verfassung und Verwaltung, Ferne gegenüber der modernen Bildung und Wissenschaft. ${ }^{7}$ Daraus lässt sich für Niebuhr in der Summe nur eine Forderung ableiten: Sachsen muss zu seinem eigenen Heil mit Preußen vereinigt werden. Das erscheint zugleich als wichtiger Schritt zur „politischen Nationaleinheit“ Deutschlands, die sich zwar noch in weiter Ferne befände, aber durch die Bildung starker Staaten, wie eben Preußen, vorbereitet werden könne. Indem die Sachsen, die nachweislich gar keine Nation bilden, der preußischen Nationalität teilhaftig werden, verlieren sie nichts, gewinnen aber alles. ${ }^{8}$ Preußen ist also für Niebuhr nicht ein beliebiger deutscher Staat unter mehreren, er ist vielmehr der eigentlich einzige deutsche Staat, und nur er besitzt demnach einen wahrhaft nationalen Charakter. Er hat zielsicher den Weg gefunden, der zu Erfolg, Macht und Größe führte, der in der Zukunft sogar die deutsche Einheit erhoffen lässt. Alle anderen deutschen Länder müssen sich an ihm messen, und sie können dann bei nüchterner Betrachtung in ihrem Eigenwert nur als eher gering befunden werden, gerade und besonders Sachsen. Diese an Niebuhrs Beispiel erkennbare vorbehaltlose Indienststellung der Historiografie zur Begründung aktueller preußischer Politik ist im Übrigen natürlich nicht dessen Erfindung. Sie lässt sich mindestens bis auf den Berliner Hofhistoriografen Samuel von Pufendorf zurückverfolgen. In dessen Werken finden sich Ende des 17. Jahrhunderts bereits mehrere der zur Zeit des Wiener Kongresses dargebote-

Abbt unter den Anforderungen des Krieges eine Auflösung der Standesschranken erkennen: Aus diesem Gesichtspunkte betrachtet, verschwindet der Unterschied zwischen Bauer, Bürger, Soldat und Edelmann. Alles vereinigt sich, und stellt sich unter dem vormals so berrlichen Namen eines Bürgers dar [...]. Man erblickt nicht mebr den Bürger, den Edelmann, den Soldaten besonders. Alles ist Bürger. Tномаs Аввт, Vom Tode für das Vaterland, in: Ders., Vermischte Werke, Zweiter Teil, Berlin/Stettin 1781, S. 16 (ND Hildesheim/New York 1978). Die 1761 erstmals publizierte Schrift steht deutlich unter dem Eindruck des Kriegserlebnisses. Der Krieg erscheint als ein besonderer Fall, der die Bande zwischen den Ständen anzieht.

7 Auf eine solche Feststellung trifft man noch gut einhundert Jahre später. Vgl. PAuL HaAke, August der Starke, Berlin/Leipzig [1927], S. 185. August der Starke hätte Haake zufolge das Wettrennen mit Preußen vielleicht doch noch gewinnen können, wenn er folgende Aufgaben in die Tat umgesetzt hätte: Ausbau des Heeres, Schaffung eines ihm ergebenen Beamtenapparates, Bruch der Macht der Stände.

8 Niebuhr, Preußens Recht (wie Anm. 1), S. 49 f. 
nen Argumentationsstränge zur Rechtfertigung des preußischen Handelns - allerdings noch ohne einen Vergleich mit Sachsen, was an dieser Stelle jedoch nicht weiter verfolgt werden kann. ${ }^{9}$ Die folgenden Darlegungen, die nur andeutenden Charakter besitzen können, wollen diese eindimensionale Einschätzung des Wesens der preußischen Geschichte in der Form eines punktuellen Vergleichs mit der sächsischen Geschichte in Frage stellen. ${ }^{10}$

Diese Fragestellung hat durchaus ihren Sinn, denn Niebuhrs Behauptungen über Preußens Vorbild auf der einen Seite und über den Charakter des sächsischen Staates und seiner Geschichte auf der anderen Seite haben bis heute Schule gemacht, wenn auch weniger in unmittelbarer Tradition zu dem eben zitierten Buch über Preußens angebliches Recht gegenüber Sachsen. Spätere Historiker stützen sich bis ins 20. Jahrhundert hinein weniger auf Niebuhrs für den Tag und die Stunde gedachte und heute nur wenig bekannte Kampfschrift, sondern z. B. auf Heinrich von Treitschke mit seiner vielgelesenen „Deutschen Geschichte im neunzehnten Jahrhundert“. Im dritten Band dieses Opus magnum, das gleichwohl Fragment blieb, wird der Stab über das Haus Wettin und das von ihm regierte Sachsen mit aller Verve gebrochen. Schon Kurfürst Moritz erscheint als Vertreter eines „ideenlosen Partikularismus“, statt kühn das nationale Ziel eines evangelischen Kaisertums zu verfolgen. Unfähigkeit, Schwäche, verräterisches Handeln prägten dann die Regierungen der folgenden Fürsten, deren „abschüssiger Weg“ in der polnischen Königskrönung Augusts des Starken ihren Abschluss fand. Für diese „undeutsche Politik“ erbrachte Sachsen ungeheure Opfer, ohne damit den schließlichen Machtverlust Preußen gegenüber verhindern zu können. Dieses Ergebnis ist für den gebürtigen Sachsen Treitschke von zwangsläufiger Natur, denn hier siegte nach seiner Ansicht das schlechterdings überlegene Prinzip: „Der lange Streit zwischen Preußen und Sachsen war nicht bloß ein Kampf um die Macht,

9 Vgl. Hans Rödding, Pufendorf als Historiker und Politiker in den „Commentarii de rebus gestis Friderici tertii“, Halle 1912; Detlef Döring, Samuel von Pufendorfs Berufung nach Brandenburg-Preußen, in: Ders., Samuel Pufendorf in der Welt des 17. Jahrhunderts. Untersuchungen zur Biographie Pufendorfs und zu seinem Wirken als Politiker und Theologe, Frankfurt a. M. 2012, S. 131-154.

10 Es geht also im Folgenden nicht um die gegenseitige zeitgenössische Wahrnehmung zwischen Preußen und Sachsen, sondern um die Sicht des heutigen Historikers. Vgl. zur zeitgenössischen Beurteilung Frank Göse, „Die Preußen hätten keine Lust zu beißen ....". Wahrnehmungsmuster im brandenburgisch-kursächsischen Verhältnis in der zweiten Hälfte des 17. Jahrhunderts und im 18. Jahrhundert, in: Cornelia Klettke/Ralf Pröve (Hg.), Brennpunkte kultureller Begegnungen auf dem Weg zu einem modernen Europa. Identitäten und Alteritäten eines Kontinents (Schriften des Frühneuzeitzentrums Potsdam 1), Göttingen 2011, S. 153-182. Vgl. zum Verhältnis zwischen Preußen und Sachsen in der Frühen Neuzeit jetzt: Preußen und Sachsen. Szenen einer Nachbarschaft. Katalog zur Ersten Brandenburgischen Landesausstellung Schloss Doberlug 2014, hrsg. von Frank Göse/Winfried Müller/Kurt Winkler/Anne-Katrin Ziesak für das Haus der brandenburgisch-preußischen Geschichte, Dresden 2014. Zur Entwicklung der Konkurrenz zwischen den beiden Mächten ist vor allem der Beitrag von Frank Göse richtungsweisend: Von der "Juniorpartnerschaft" zur Gleichrangigkeit. Das brandenburgisch-sächsische Verhältnis im 16. und 17. Jahrhundert, in: ebd., S. 44-51. 
sondern auch ein Kampf zweier Staatsgedanken; das politische Königtum der Hohenzollern siegte über die Frivolität fürstlicher Selbstvergötterung. "11 Was auch immer im Einzelnen mit dieser und anderen Gegenüberstellungen zwischen Preußen und Sachsen gemeint ist, entscheidend ist die Behauptung, auf preuBischer Seite sei über die Generationen hinweg eine zielstrebige, realistisch begründete Machtpolitik des schrittweisen Staatsaufbaus betrieben worden, die bald, gleich ob bewusst oder eher noch unbewusst, auf die Einheit Deutschlands zustrebte und diese dann auch herbeiführte.

Die Vorstellung vom besonderen, vom geradezu einzigartigen Charakter Preußens blieb bis tief in das 20. Jahrhundert lebendig. Ich erwähne nur zwei bewusst aus dem Bereich der nichtwissenschaftlichen Literatur entnommene Beispiele, ${ }^{12}$ in denen Sachsen im herausgehoben negativen Kontrast zur glanzvollen Entwicklung Preußens steht: Der einstmals vielgelesene Schriftsteller Arthur Moeller van den Bruck, einer der führenden Vertreter der nach dem Ende des Ersten Weltkrieges in Deutschland einflussreichen Konservativen Revolution, hat in seinem Werk „Der Preußische Stil“ das Preußentum als den Geist bezeichnet, „der in Deutschland die Schwärmerei durch den Willen, den Schein durch die Sache und Sachlichkeit ablöste und unter uns wieder die Sendung zur Tat übernahm." 13 Wie eine Illustration dieser Feststellung wirkt dann eine Beschreibung der Heimkehr des Soldatenkönigs Friedrich Wilhelm I. von einem Besuch Dresdens: Aus dem „feinen schwelgerischen sächsischen Fasching, Hofleben, Welttreiben“ reiste er „fast empört“ zurück „in seine harte Mark, sein nüchternes Berlin, seinen sparsamen Haushalt“. ${ }^{14}$ Dem sächsischen Schein tritt die preußische Sachlichkeit und Nüchternheit gegenüber. Die Schwärmerei, das wirklichkeitsfremde Agieren steht im scharfen Kontrast zu einer Haltung, die gegründet ist auf einen festen Willen, auf Ernst und Umsicht. Was also in Sachsen stets fehlte, das war eine geschichtlich

11 Heinrich von Treitschke, Deutsche Geschichte im neunzehnten Jahrhundert, Teil 3: Bis zur Juli-Revolution, Leipzig 1927, S. 482. Immerhin schenkt Treitschke Sachsen einige Aufmerksamkeit (30 Seiten). In Thomas Nipperdeys ,Nachfolgewerk' (Thomas NipPERDEY, Deutsche Geschichte 1800-1866. Bürgerwelt und starker Staat, München 1983) kommt Sachsen in der Darstellung der Zeit des Vormärz erst gar nicht vor. Auch in Christopher Clarks vielgerühmter Darstellung der preußischen Geschichte spielt die Konkurrenz zwischen Preußen und Sachsen so gut wie keine Rolle, auch wenn eher beiläufig an einer Stelle von der „langjährigen Rivalität zwischen Preußen und Sachsen“ die Rede ist. Vgl. Christopher Clark, Preußen. Aufstieg und Niedergang 1600-1947, München 2007 [englische Erstausgabe 2006], S. 362 f. Auch in kultureller Hinsicht sieht Clark keinerlei Verbindungen zwischen Sachsen und Preußen. Dem, Wettstreit' zwischen Preußen und Sachsen hat der Historiker Paul Haake ein ganzes Buch gewidmet: Paul HaAke, Kursachsen oder Brandenburg-Preußen? Geschichte eines Wettstreits, Berlin 1939. Die Argumentation Haakes entspricht der Treitschkes, nur wird immerhin der Versuch unternommen, die am Geschehen beteiligten Personen etwas differenzierter zu beurteilen.

12 Diese belegen weitaus besser die Verbreitung von Klischeevorstellungen über das engere fachwissenschaftliche Publikum hinaus.

13 Arthur Moeller van den Bruck, Der Preußische Stil, Breslau 31931, S. 21.

14 Ebd., S. 83. 
legitimierte Staatsidee als Grundlage wahrhaft großer Politik. Ein noch bekannterer und im Gegensatz zu Moeller van den Bruck auch noch nach 1945 vielgelesener Autor, Reinhold Schneider, stellte in einem 1933 erstmals erschienenen Buch Sachsen und Preußen in einen scharfen Kontrast zueinander. Legitimiert ist nach seiner Überzeugung ein Staat nur dann, wenn er unter einer ,treibenden Notwendigkeit“ steht. Sachsen aber „hatte im 18. Jahrhundert keine Notwendigkeit mehr; und damit auch keine geschichtliche Größe mehr zu erwarten. Nur der Auftrag erhält den Einzelnen wie den Staat am Leben; und das eigentliche Leben währt nicht eine Minute über den Augenblick hinaus, in dem sich der Auftrag erfüllt." 15 An Preußen dagegen ist ein „Auftrag" ergangen, den Friedrich II. vollstreckte: „Die Ahnen [...], das ganze Bewußtsein der Tradition seines Hauses, seiner Verantwortung als Haupt einer begründeten, noch nicht vollendeten Macht; das Gefühl einer furchtbaren inneren Gefahr, des drohenden Verlustes kaum erworbener Kräfte: dies alles drängte den jungen König zur Tat.“16

\section{Preußen und Sachsen als europäische Mächte}

Das Irrlichtern der Dresdner Politik, deren Schwärmerei, um nochmals mit Moeller van den Bruck zu sprechen, dokumentiert sich in den Augen der Kritiker vor allem in der sächsisch-polnischen Union von 1697 bis 1763. Deren Verurteilung bildet fast einen Gemeinplatz wenigstens der älteren Historiografie. ${ }^{17}$ Ich nenne wiederum nur ein Beispiel, allerdings ein neueres. Für Karlheinz Blaschke, seit

15 Reinhold Schneider, Die Hohenzollern (Fischer Bücherei 242), Frankfurt a. M./ Hamburg 1958 [Erstausgabe 1933], S. 124 f.

16 Ebd., S. 129.

17 So heißt es in dem weit verbreiteten, vielbändigen Werk „Spamers Illustrierte Weltgeschichte" kurz und bündig: In politischer Beziebung dagegen hat die Erwerbung der polnischen Flitterkrone dem sächsischen Lande fast nichts als Unbeil gebracht. (Spamers Illustrierte Weltgeschichte. Mit besonderer Berücksichtigung der Kulturgeschichte, Bd. 7: Vom Verfall der bourbinischen Macht bis zum Beginn der großen französischen

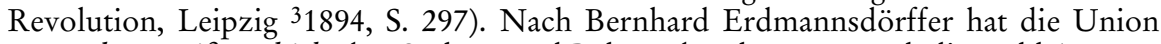
namenloses Mißgeschick über Sachsen und Polen gebracht, wenn auch die Wahl Augusts als gleichzeitige Niederlage Frankreichs im deutschen Interesse gelegen hätte (BERNHARD ERdmannsdörfFer, Deutsche Geschichte vom Westfälischen Frieden bis zum Regierungsantritt Friedrichs des Großen 1648-1740, Bd. 2, Meersburg/Naunhof/ Leipzig 1932, S. 95). Zu den wichtigsten neueren Arbeiten, die eine gegenteilige Position beziehen, gehört René Hanke, Zur Beurteilung der sächsisch-polnischen Union (16971763). Grundlagen, Entwicklungsmöglichkeiten und Vorteile, in: NASG 74/75 (2003/ 2004), S. 227-275. Vgl. auch Ders., Brühl und das Renversement des alliances. Die antipreußische Außenpolitik des Dresdner Hofes 1744-1756 (Historia profana et ecclesiastica 15), Berlin/Münster 2006. Nach Hanke bot die Union für Sachsen die durchaus realistische Möglichkeit, sich neben Preußen und Österreich als selbstständige Macht zu behaupten. Wäre Sachsen diesen Weg nicht gegangen, wäre das „der wirkliche Fehler" gewesen, da damit die Niederlage im Konkurrenzkampf mit den anderen deutschen Mächten vorweggenommen worden wäre. Hanke, Zur Beurteilung (wie Anm. 17), S. 275. 
Jahrzehnten der bekannteste sächsische Landeshistoriker, ging dem Kurfürstentum Sachsen der Frühen Neuzeit der „Wille zur Macht“ ab, der das politische und militärische Instrumentarium hätte schaffen können, um „in die große deutsche und europäische Politik“ einzugreifen. Der dann doch von August dem Starken unternommene Versuch, über die polnische Krone „große Politik“ zu betreiben, erwies sich als „dilettantisch“ und „unverantwortlich“, getragen allein von egoistischen Motiven eines triebgesteuerten Monarchen. ${ }^{18}$ Ganz anders, weiß der Dresdner Historiker zu urteilen, hätte Friedrich August handeln müssen: „Ein Kurfürst von Sachsen, der seiner Aufgabe vor der Geschichte seines Hauses und seines Landes gewachsen gewesen wäre, hätte wie ein kluger Schachspieler die möglichen Züge seines Gegners - und Preußen war im frühen 18. Jahrhundert bereits als Gegner Sachsens zu erkennen - vorausbedenken müssen“. Da es in Sachsen im Gegenteil zu Preußen aber keine „tragende Staatsidee“ gab, bzw. man sich ihrer nicht bewusst wurde, sei dies nicht geschehen. ${ }^{19}$

In Verbindung zum Vorwurf des Fehlens einer großen politischen Leitidee und einer darauf gegründeten konsequenten und systematischen Machtpolitik steht bei den meisten Historikern die scharfe Kritik am Konfessionswechsel Augusts des Starken, denn vor allem in seiner Funktion als Vormacht des Luthertums habe Sachsen im Reich Geltung und Einfluss besessen. Kein Geringerer als Ernst Troeltsch fasst das mit einem Satz zusammen: „Mit dem leichtsinnigen Übertritt des Kurhauses zum Katholizismus war seine Rolle für das Luthertum aus-

18 Karlheinz Blaschke, Albertinische Wettiner als Könige von Polen - ein Irrweg sächsischer Geschichte, in: Sachsen und Polen zwischen 1697 und 1765. Beiträge der wissenschaftlichen Konferenz vom 26. bis 28. Juni 1997 in Dresden (Saxonia 4/5), hrsg. vom Verein für Sächsische Landesgeschichte e. V., Dresden 1998, S. 52-76. Blaschke hat seine Beurteilung der Politik Augusts des Starken und der Union zwischen Polen und Sachsen in vielen Publikationen wiederholt.

19 Karlheinz Blaschke, Kritische Beiträge zu einer Biographie des Kurfürsten Friedrich Augusts I. von Sachsen, in: August der Starke und seine Zeit. Beiträge des Kolloquiums vom 16./17. September 1994 auf der Festung Königstein (Saxonia 1), hrsg. vom Verein für sächsische Landesgeschichte e. V., Dresden 1995, S. 7-13, hier S. 10. Schwere Manöverkritik äußert ebenso Helmut Kretzschmar: Der Große Kurfürst „bahnte sich durch eine skrupellose, den Reichsorganismus sprengende Aktivität den Weg ins freie Fahrwasser des großen europäischen Kräftespiels, während die Johann George in Sachsen [...] im ganzen Reichspolitik trieben, sei es [...] aus wirklichem Verbundenheitsgefühl gegenüber dem Reichsgedanken oder aber wohl aus der Unlust, eigene Wege zielsicher zu verfolgen und aus lebendigem Erfassen der politischen Gesamtlage heraus kühn zu handeln." Rudolf KötzschKe/Hellmut Kretzschmar, Sächsische Geschichte. Werden und Wandlungen eines deutschen Stammes und seiner Heimat im Rahmen der deutschen Geschichte, Frankfurt a. M. 1965 [Erstausgabe 1935], S. 265). Das Thema gibt überhaupt immer wieder manchem Historiker Anlass, sich am Schreibtisch als unerschrockenen (,kühnen') und konsequent machiavellistisch orientierten Machtpolitiker zu gerieren, der den richtigen, von den handelnden historischen Personen leider aber nicht beschrittenen Weg genau kennt. Ein besonders deutliches Beispiel bietet HaAke, Kursachsen (wie Anm. 11), zum Beispiel S. 198-205. 
gespielt.“"20 Die Aufgabe dieser so gewichtigen Position habe dem konkurrierenden Preußen die Rolle einer Schutzmacht des Protestantismus verschafft und damit dessen machtpolitischen Aufstieg in einem ganz erheblichen Maße befördert. Die Konversion der Hohenzollern zum Calvinismus achtzig Jahre zuvor wird dagegen fast durch die Bank weg von den Historikern als zukunftsträchtiger Schritt gewürdigt. Mit der Annahme des reformierten Bekenntnisses habe, schreibt Otto Hintze in seinem verbreiteten Buch „Die Hohenzollern und ihr Werk“, Johann Sigismund „seinem Hause einen Talisman zugeeignet, dessen moralisch-politische Kraft in späteren Generationen wirksam werden konnte."21 Wir kommen nochmals darauf zurück.

Die eben angesprochenen Themen bilden einen höchst facettenreichen Komplex, auf den hier nur mit einigen Hinweisen eingegangen werden kann. Geschichte ist, um das vorweg zu sagen, in einem höheren Maße als meist angenommen von Zufällen abhängig. Sie bieten den Akteuren diese oder jene Möglichkeit des Handelns, die ergriffen werden kann oder auch nicht. Dazu gehören in dem uns beschäftigenden Zeitraum Erbansprüche auf andere Ländergebiete, die zumeist durch das Aussterben regierender Geschlechter akut wurden. Im Falle Preußens bot sich so die Chance, im 17. Jahrhundert wichtige Territorien wie Kleve, Mark und Ravensberg im Westen sowie das herzogliche Preußen und das Herzogtum Pommern im Osten zu erwerben, womit entscheidende Voraussetzungen für den folgenden Machtaufstieg Preußens geschaffen waren. Innerhalb des Kreises der sehr wenigen Reichsstände, die nach dem Westfälischen Frieden machtmäßig überhaupt in der Lage waren, eine größere oder gar europäische Politik zu betreiben, verschaffte der Gewinn eines Territoriums, das, wenn auch

20 Ernst Troeltsch, Protestantisches Christentum und Kirche in der Neuzeit, in: Geschichte der christlichen Religion (Die Kultur der Gegenwart, Teil I, Abteilung IV., 1. II. Hälfte), Leipzig/Berlin 21922, S. 431-755d, hier S. 530.

21 Отто Hintze, Die Hohenzollern und ihr Werk. Fünfhundert Jahre vaterländischer Geschichte, Berlin 1915, S. 164. In einem schon 1906 erschienenen Aufsatz geht Hintze noch weiter: Erst der Übertritt zum Calvinismus habe den Weg für Preußens spätere Rolle als Einiger Deutschlands frei gemacht, denn dadurch sei das Land „in die Luft einer großen Politik“ versetzt worden, hätte doch der Calvinismus den großen Kampf gegen die „katholische Restauration“ geführt. Dagegen setzt Hintze die „dumpfe Enge des kleinstaatlichen Luthertums“. Sachsen wird hier nicht genannt, aber Hintze dürfte u. a. dieses Beispiel im Auge gehabt haben. Vgl. Ders., Die Epochen des evangelischen Kirchenregiments in Preußen, in: Otto Büsch/Wolfgang Neugebauer (Hg.), Moderne Preußische Geschichte. Eine Anthologie, Bd. 3 (Veröffentlichungen der Historischen Kommission zu Berlin 52), Berlin/New York 1981, S. 1217-1242, hier S. 1219. Bekanntlich ist der entscheidende Kampf gegen die katholische Restauration vor allem vom streng lutherischen Schweden und schließlich vom katholischen Frankreich geführt worden. Von zentraler Bedeutung für den erfolgreichen Weg Preußens ist der Übertritt zum Calvinismus auch für Carl Hinrichs, Preussen als historisches Problem, in: Ders., Preussen als historisches Problem. Gesammelte Abhandlungen, hrsg. von Gerhard Oestreich (Veröffentlichungen der Historischen Kommission zu Berlin beim Friedrich-Meinecke-Institut der Freien Universität Berlin 10), Berlin 1964, S. 15-39, hier S. 23. 
nur in Fetzen, von der holländischen bis zur litauischen Grenze reichte, bei allen Problemen und Gefährdungen auch unbedingt Vorteile: Preußen war Akteur bei fast allen großen politischen Auseinandersetzungen und Entwicklungen des nördlichen Europas. Über eine solche Position verfügten die Konkurrenten Brandenburgs nicht. Wenn Heinz Schilling schreibt, Kursachsen habe den „europäischen Handlungshorizont“ verspielt und hätte so die Hoffnung aufgeben müssen, „auf den traditionellen Wegen in den Kreis der Großmächte vorzustoßen“, 22 daher der zweifelhafte Griff nach der Krone Polens, so fragt sich, was mit der Bezeichnung „traditioneller Weg“ eigentlich genauer gemeint ist. Die Tatsache, dass alle potenteren Reichsstände um 1700 versuchten, über den Erwerb auswärtiger Kronen zu Mächten europäischen Gewichts aufzusteigen, zeigt, dass man dieses Ziel als ein bloßes Glied des Deutschen Reiches und damit als Lehensträger des Kaisers nicht erreichen konnte. Insofern entsprang der Erwerb der polnischen Königskrone keiner Verlockung eines „blendenden Irrlichts“"23, der ein einzelner realitätsfremder Fürst erlag, August der Starke, sondern entbehrte nicht der Folgerichtigkeit. Schon Augusts Vorgänger spielten mit diesem Gedanken, und auch dem brandenburgischen Großen Kurfürsten ist er Jahre zuvor nicht fremd gewesen. Dass Preußen schließlich die gleiche Strategie auf einem anderen Weg mit dauerndem Erfolg anwenden konnte, hatte den entscheidenden, eben schon erwähnten Vorteil zum Hintergrund, seit fast einhundert Jahren ein unabhängiges Territorium zu besitzen, nämlich Ostpreußen, das außerhalb des Reiches lag und doch kein dem deutschen Sprach- und Kulturverband fremdes Land war. Bei allen anderen Staatenverbindungen zwischen deutschen Reichsständen und auswärtigen Staaten haben entweder letztere infolge ihrer Übermacht die jeweilige Union eindeutig dominiert, das beste Beispiel bietet England, oder es ist über kurz oder lang zum Bruch der Verbindung gekommen.

„Herrscher in der Doppelpflicht“ bildeten also in der Frühen Neuzeit keine ganz ausgesprochenen Seltenheiten. Der moderne Gedanke, dass verschiedene, in separaten Staaten organisierte Ethnien nicht von einer Hand regiert werden könnten oder sollten, spielte vor dem Aufstieg des Nationalismus im 19. Jahrhundert noch keine Rolle. Dass das polnische Experiment schließlich scheiterte, lag in der Hauptsache an den unglücklichen außenpolitischen und militärischen Verwicklungen, in die die sächsisch-polnische Union im Verlauf ihrer Existenz fortwährend gezogen wurde. ${ }^{24}$ Im Übrigen rissen die Verbindungen zwischen Polen und

22 Heinz Schilling, Höfe und Allianzen. Deutschland 1648-1763 (Siedler Deutsche Geschichte), Berlin 1994, S. 165.

23 HaAke, Kursachsen (wie Anm. 11), S. 205.

24 Heinz Duchhardt, ein guter Kenner der internationalen Beziehungen in der Frühen Neuzeit, sieht in der Vernachlässigung des sächsischen Stammlandes zugunsten Polens die Ursache für den Niedergang Sachsens als europäische Macht. Die Stunde für eine „anspruchsvollere Außenpolitik“ Sachsens sieht Duchhardt daher merkwürdigerweise erst nach dem Siebenjährigen Krieg gegeben. Hier wird verkannt, dass erst die Verbindung mit Polen dem sächsischen Kurfürsten wirkliches internationales Gewicht verlieh. Vgl. Heinz Duchinardt, Balance of Power und Pentarchie. Internationale 
Sachsen nach 1763 nicht ab. Die Möglichkeiten einer Rückkehr der Wettiner auf den polnischen Thron wurden immer wieder ventiliert, die polnische Verfassung von 1791 bot Kurfürst Friedrich August III. (I.) offiziell die Krone Polens an, und von 1807 bis 1813 regierte der inzwischen zum König von Sachsen avancierte Friedrich August das Herzogtum Warschau. Um eine so ganz und gar unnatürliche Verbindung kann es sich also bei der Union zwischen Polen und Sachsen nicht gehandelt haben. Ob die sächsischen Kurfürsten geschickte Schachspieler gewesen sind oder eben nicht, vermag ich nicht zu beurteilen. Sehr wohl aber meine ich, dass sie politische Konzeptionen verfolgten, die nicht einfach als pures Abenteurertum abqualifiziert werden können. Das angeblich ganz anders orientierte politische Handeln Preußens trug in Wirklichkeit keinen wesentlich anderen Charakter. Die angebliche deutsche Sendung, die spätestens seit dem 17. Jahrhundert der Leitstern der Berliner Politik gewesen sein soll, hat es in den Köpfen der damals Handelnden als Vorstellung nie gegeben. Was man verfolgte, das waren preußische Interessen oder wenigstens das, was man dafür hielt. Das bildet eine schon seit langer Zeit gängige Erkenntnis, deren Erinnerung aber im Blick auf so manche nach wie vor auf Preußen konzentrierte neuere Darstellung der deutschen Geschichte als vielleicht nicht überflüssig erscheint. Ansonsten wurden beide innerhalb der jeweiligen Landesgeschichte herausragenden Potentaten, Friedrich II. und August II., in ihrem Griff nach Kronen und Ländern vom gleichen Antrieb beherrscht, von der Sucht nach Ruhm. Als es um die Bewerbung um die polnische Krone ging, schrieb August am 8. November 1697 an den Grafen Jakob Heinrich von Flemming, dessen Verhandlungsgeschick der schließliche Erfolg des ganzen Unternehmens zu verdanken war: Mein höchster Ebrgeiz ist Rubm, wonach ich bis an mein Lebensende streben werde. ${ }^{25}$ Für König Friedrich bildete Ruhm ebenfalls das höchste Ziel, erreichbar zuerst und vor allem durch militärische Erfolge. Den im Dezember 1740 in Richtung Schlesien ausrückenden Offizieren rief er zu: Leben Sie wobl, brechen Sie auf zum Rendezvous des Rubmes, wohin ich Ibnen ungesäumt folgen werde. ${ }^{26}$

\section{Konfessionspolitik in Preußen und Sachsen}

Mit der Beurteilung der Politik Sachsens vor allem gegenüber dem Reich steht, wie schon erwähnt, die konfessionelle Frage in einer engen Verbindung. Friedrich Augusts I. Konversion in Baden bei Wien war in der Sicht seiner zahlreichen Kritiker der verheerendste Fehler, den er begehen konnte. Er katapultierte ihn bzw.

Beziehungen 1700-1785 (Handbuch der internationalen Beziehungen 4), Paderborn u. a. 1997, S. 208.

25 Zitiert nach Reinhard Delau, August der Starke. Bilder einer Zeit, Halle/Leipzig 1989, S. 34.

26 Zitiert nach Jürgen Luh, Der Große. Friedrich II. von Preußen, Berlin 2011, S. 51. Luh bietet zahlreiche weitere Belege für Friedrichs Ruhmbegierde. 
Sachsen reichspolitisch ins Abseits. Nach Ernst Troeltsch, seiner bis heute zu recht geltenden hohen Anerkennung als Geschichts- und Kulturphilosoph wegen sei er hier nochmals zitiert, hatte Kursachsen Brandenburg gegenüber aufgrund der „lutherischen Passivität und dem Konservatismus albertinischer Selbstsucht“ ohnehin schon an Boden verloren; jetzt ging ihm seine „führende Stellung im Luthertum“ gänzlich verlustig. Preußen dagegen wird infolge des Glaubenswechsels seines Herrscherhauses zum Calvinismus zu einem Hort der Toleranz. ${ }^{27}$ „Es war ein neues Prinzip“, so Otto Hintze, „das damit in die deutsche Staatenwelt eintrat." 28 Das ist nach Urteil der zitierten Sachkenner zuerst auf den geradezu als intuitiv zu wertenden Konfessionswechsel des Kurfürsten zurückzuführen, habe aber auch eine traditionell verankerte Mäßigung der lutherischen Kirche in Brandenburg zum Hintergrund. Das preußische Luthertum sei im Gegensatz zu Sachsen, meint Troeltsch, seit Johann Sigismund „zur Duldung anderer Religionen geneigt und insofern nicht mehr das alte Luthertum. "Das habe, so die daraus abgeleitete äußerst folgenreiche und anspruchsvolle These, Preußens „Zukunft als Großmacht ermöglicht“.29 Dass sich das unter preußischer Führung 1871 geeinte Deutschland nach Vorstellung der Hohenzollern als dezidiert protestantisches Reich verstehen sollte, ist bekannt, es genügt die Erinnerung an den bald folgenden Kulturkampf. Dahinter steht nicht zuletzt die zur Legende stilisierte Auffassung, Preußen sei von jeher Schutzmacht, Bollwerk und Bannerträger des Protestantismus gewesen.

Wir werfen, was diese Frage angeht, zuerst einen Blick auf Preußen, ${ }^{30}$ dann auf Sachsen. Die Auffassung von der angeblichen Toleranz, die seit Übertritt des Kur-

27 Vgl. Anm. 20.

28 Hintze, Die Hohenzollern (wie Anm. 21), S. 165. Geradezu ,hymnisch` über die Folgen des Konfessionswechsels Johann Sigismunds äußert sich Hans-Joachim Schoeps: Der Kurfürst habe „eine seiner Zeit weit vorauseilende moderne Tradition religiöser Toleranz" begründet. Im Gegensatz zu allen anderen europäischen Staaten habe er seine Untertanen nicht zur Annahme der eigenen Konfession gezwungen usw. Damit wird u. a. verkannt, dass Johann Sigismund eine Konfession angenommen hatte, die reichsrechtlich überhaupt nicht anerkannt war, der Grundsatz „cuius regio, eius religio “ für ihn also gar nicht galt. Vgl. Hans-Joachim Schoeps, Preussen. Geschichte eines Staates, Berlin ${ }^{7} 1967$, S. 28 f. Eine ähnliche Position vertritt das ebenfalls weit verbreitete Buch von Rudolf von Thadden, Fragen an Preußen. Zur Geschichte eines aufgehobenen Staates, München 1981 (hier zitiert nach einer Ausgabe München 1987, S. 47 f.): Preußen habe durch den Konfessionswechsel die „lutherische Zaghaftigkeit“ hinter sich gelassen und einen "Gegenpol zum katholischen Süden des Reiches“ gebildet. Schließlich habe Preußen „so unerbittlich die Konsequenz aus der Schwäche und dem Verfall des Reichs" gezogen und sich von ihm getrennt. Das sind freilich alles Behauptungen, denen eine einigermaßen überzeugende Begründung weitgehend fehlt.

Vgl. Hans-Christof Kraus, Staat und Kirche in Brandenburg-Preußen unter den ersten beiden Königen, in: Joachim Bahlcke/Werner Korthaase (Hg.), Daniel Ernst Jablonski. Religion, Wissenschaft und Politik um 1700 (Jabloniana 1), Wiesbaden 2008, S. 47-85, mit zahlreichen Verweisen zur neueren Literatur. 
hauses zum Calvinismus als neues Prinzip in Brandenburg geherrscht habe, ${ }^{31}$ hat sich trotz aller gegenteiligen Forschungsergebnisse bis heute wenigstens im breiteren Bewusstsein erhalten. Nichts ist irriger. Die interkonfessionellen Auseinandersetzungen, die bis in das 18. Jahrhundert hinein Preußen immer wieder erschütterten, haben sowohl der inneren Stabilität des Staates als auch seinem äußeren Ansehen Abbruch getan. Den Katholiken wurde keine generelle Toleranz eingeräumt, ${ }^{32}$ sondern nur eine durch die Friedensschlüsse von 1555 und 1648 vorgeschriebene Duldung, die außerhalb der Reichsgrenzen keine Gültigkeit besaß. Das belegt u. a. das scharfe 1694 geführte Vorgehen gegen den Königsberger Theologieprofessor Johann Philipp Pfeiffer, der als heimlicher „Papist“ verdächtigt wurde und zum Widerruf seiner Lehren gezwungen werden sollte. Vorsitzender der Untersuchungskommission war der Rechtsphilosoph Samuel von Pufendorf, der in der Literatur oft als Vorkämpfer der Religionsfreiheit gefeiert wird. ${ }^{33}$

Von wesentlicherer Bedeutung war das Verhältnis zwischen der lutherischen Bevölkerungsmehrheit ${ }^{34}$ und dem reformierten Herrscherhaus und dessen zumeist höfischen Umkreis. Von einem „Kirchenfrieden“35 lässt sich hier kaum sprechen. Wir haben dafür keinen besseren Zeugen als den im 19. Jahrhundert zu einem Apologeten des Preußentums stilisierten und eben schon erwähnten Samuel von Pufendorf, seit 1688 offiziell bestallter Berliner Hofhistoriograf. Folgt man

31 Vgl. Leopold von Ranke, Zwölf Bücher preussischer Geschichte, Bd. 2, München 1930, S. 322 f.: Preußen habe sich mit seiner Toleranzpolitik von allen anderen deutschen Staaten unterschieden. Als Gegenbeispiel zu Preußen nenntRankebemerkenswerterweise Sachsen unter August dem Starken. Der Übertritt zum Katholizismus sei dort für eine politische Karriere fast Voraussetzung gewesen. Neuere Autoren urteilen differenzierter, beschreiben aber weiterhin die Verhältnisse in Preußen als geprägt von „gegenseitiger Toleranz und Achtung der Konfessionen“; Hartmut Lemmann, Das Zeitalter des Absolutismus. Gottesgnadentum und Kriegsnot (Christentum und Gesellschaft 9), Stuttgart u. a. 1980, S. 87. Weitgehende Kritik an der Theorie, Brandenburg-Preußen sei ein Vorreiter der Toleranz gewesen, hat Jürgen Luh in verschiedenen Beiträgen geäußert; z. B. JÜRgEN LuH, Die Religionspolitik Friedrichs III./I., in: Preußen 1701. Eine europäische Geschichte, Bd. 2: Essays, hrsg. vom Deutschen Historischen Museum und der Stiftung Preußische Schlösser und Gärten Berlin-Brandenburg, Berlin 2001, S. 156-164. Eine die Kritik Luhs aufnehmende, aber doch grundsätzlich an der älteren Toleranzthese festhaltende Position bezieht Kraus, Staat und Kirche (wie Anm. 30), S. 81-85. Dabei wird ausdrücklich darauf verwiesen, dass die Katholiken von dieser „begrenzten Religionstoleranz" ausgenommen blieben.

32 Aus außenpolitischen Gründen (z. B. im Blick auf den geplanten Erwerb der Königskrone) musste allerdings immer wieder Rücksicht auf die katholischen Minderheiten einzelner Landesteile genommen werden; das ändert aber nichts an der generell zutiefst misstrauischen Haltung gegenüber dem Katholizismus. Zur preußischen Politik gegenüber dem Katholizismus um 1700 vgl. Frank GösE, Friedrich I. (1657-1713). Ein König in Preußen, Regensburg 2012, S. 308-314.

33 Vgl. Detlef Döring, Pufendorf-Studien. Beiträge zur Biographie Samuel von Pufendorfs und zu seiner Entwicklung als Historiker und theologischer Schriftsteller (Historische Forschungen 49), Berlin 1992, S. 122-129.

341740 bestand die preußische Bevölkerung zu fast $90 \%$ aus Lutheranern, 3,3 \% waren reformiert. Vgl. Kraus, Staat und Kirche (wie Anm. 30), S. 48.

35 Lehmann, Zeitalter (wie Anm. 31), S. 87. 
der allgemeinen Auffassung, war er einer derjenigen, die die geistigen Grundlagen für die Toleranz der brandenburgischen Herrscher gelegt haben sollen. ${ }^{36}$ An einen seiner Leipziger Bekannten schreibt er: Von den wirklichen Geheimen Räten sei nur noch einer lutherisch. Die gantze Cantzley bestebt aus reformirten. Und werden data opera die lutherischen ausgeschloßen, und die reformirten Räthe brauchen auch secretairs von ibrer religion. Und ziehet sich von allen orten und enden was reformirt ist nach Berlin. ${ }^{37}$ Diese Beobachtung widerspiegelt in der Praxis ganz den von Kurfürst Friedrich Wilhelm I. in seinem Testament entworfenen Richtlinien, wonach Subiecta von der Revormirten Religion [...] fur andere zu denen bedinungen vndt officien, zu hoffe vndt im Lande angestellt werden sollen. Seien keine Reformierten verhanden, sollten sie aus der frembde geholt werden. Der Kurfürst geht noch weiter. Auch auf die inneren Belange der lutherischen Kirche selbst hat die landesherrliche Gewalt nach Möglichkeit Einfluss zu nehmen. Bei den Lutheranern seien die groben greulen des Papismus noch nicht gänzlich abgeschafft worden, sodass Sorge zu tragen ist, diese mitt gutter manir zu beseitigen. ${ }^{38}$ Dabei ist zu beachten, dass zur Zeit der Niederschrift des Testamentes die Auseinandersetzungen um die Toleranzedikte des Kurfürsten aus den Jahren 1662 und 1664 die Gemüter der Lutheraner erregten, da sie hier wohl nicht zu Unrecht einen Versuch erblickten, die lutherischen Bekenntnisschriften außer Kraft zu setzen. ${ }^{39}$ Über Jahrzehnte hinweg erschütterten in Preußen heftigste Streitschriftenkriege zu konfessionellen Streitpunkten das Gemeinwesen. ${ }^{40}$ Ich verweise nur auf die Auseinandersetzungen um den lutherischen Kopenhagener Hofprediger Hektor Gottfried Masius, der die Behauptung aufgestellt hatte, allein die lutherische Lehre garantiere einem Landesherrn die Sicherheit seiner Herrschaft, nicht aber und keinesfalls die reformierte Konfession. Dagegen wurde in Brandenburg von calvinistischer Seite aufs schärfste und heftigste protestiert, was

36 Vgl. z. B. ebd.

37 Pufendorf an Rechenberg, 24. Oktober 1691, in: Samuel Pufendorf, Gesammelte Werke, Bd. 1: Briefwechsel, hrsg. von Detlef Döring, Berlin 1996, S. 330. Pufendorfs Verhältnis zu den Calvinisten war eher gespannt. Die gerade auch in Preußen befürworteten Unionsversuche zwischen den beiden protestantischen Kirchen wurden von ihm mit Misstrauen verfolgt. Zur generellen Benachteiligung der lutherischen Kirche zugunsten der reformierten Konfession vgl. die zahlreichen Beispiele bei GösE, Friedrich I. (wie Anm. 32), S. 314-320. Diese belegen u. a. Pufendorfs Behauptung, dass frei werdende Ämter möglichst mit Reformierten besetzt wurden.

38 Richard Dietrich (Bearb.), Die politischen Testamente der Hohenzollern (Veröffentlichungen aus den Archiven Preußischer Kulturbesitz 20), Köln/Wien 1986, S. 182. Das Testament stammt aus dem Jahre 1667.

39 Vgl. Klaus Deppermann, Die Kirchenpolitik des Großen Kurfürsten, in: Pietismus und Neuzeit 6 (1980), S. 99-114.

40 Zum gespannten Verhältnis zwischen Lutheranern und Reformierten in der Hauptstadt Berlin vgl. die viele Beispiele bietende Darstellung von Walter Wendland, Siebenhundert Jahre Kirchengeschichte Berlins (Berlinische Forschungen 3), Berlin/Leipzig 1930, S. 73-103, 220-240. 
wiederum ähnlich bittere Repliken auf lutherischer Seite hervorrief. ${ }^{41}$ Waren das Kämpfe, die eher die intellektuellen Kreise beschäftigten, so erreichte das Ringen um den Exorzismus bei der Taufe die Ebene der durchschnittlichen Gemeindemitglieder. Das kann und soll an dieser Stelle nicht im Einzelnen entwickelt werden. Genug, dass nicht Harmonie und gegenseitiges Gewährenlassen die konfessionelle Atmosphäre in Brandenburg-Preußen bestimmten, sondern Spannung, Misstrauen und Argwohn. Als „Talisman“ erwies sich der Religionswechsel hier wahrlich nicht. Im Laufe des 18. Jahrhunderts trat, im Zusammenhang mit dem allmählichen Zurücktreten der konfessionellen Gegensätze im allgemeinen Bewusstsein, zwar eine Lockerung dieser Verhältnisse ein, dass die Gegensätze gleichwohl keineswegs völlig verschwanden, zeigt die schwierige Geschichte der preußischen Kirchenunion im frühen 19. Jahrhundert. ${ }^{42}$

Im Gegensatz zu den Vorgängen in Preußen wurde und wird der Konfessionswechsel in Sachsen allgemein als ein großer Fehler des Hauses Wettin gewertet, weil er, so hörten wir bereits, Sachsen um die Führung der lutherischen Stände im Reich gebracht habe. Der Übertritt Friedrich Augusts zum Katholizismus, so würde ich gegen diese Behauptung als Gegenthese setzen wollen, darf nicht als rein innerdeutsche Angelegenheit betrachtet werden, in der die Leitung der protestantischen Reichsstände im Mittelpunkt stand. Jener Schritt versetzte den Kurfürsten über die anschließende Wahl zum polnischen König in die Reihe der großen europäischen Entscheidungsträger; darauf kam es an. War zuvor der bedeutendste Hof, mit dem man Heiratsverbindungen eingehen konnte, ein zentrales Instrumentarium neuzeitlicher Außenpolitik, der lutherische Hof in Kopenhagen, ${ }^{43}$ so stand jetzt der Weg zu den Zentren wirklicher Macht und wirklicher Ausstrahlung in europäischen Dimensionen offen - nach Wien und nach Paris. Dieser Weg ist auch konsequent beschritten worden. Zeitweise stand dahinter kein geringerer Gedanke als der Erwerb der deutschen Kaiserkrone. Auch bei der Besetzung der geistlichen Wahlfürstentümer, deren immer noch große Rolle im Reich ich nicht erläutern muss, konnten nun die Albertiner, im Gegensatz zu den

41 Vgl. Frank Grunert, Zur aufgeklärten Kritik am theokratischen Absolutismus. Der Streit zwischen Hector Gottfried Masius und Christian Thomasius über Ursprung und Begründung der „summa potestas“, in: Friedrich Vollhardt (Hg.), Christian Thomasius (1655-1728). Neue Forschungen im Kontext der Frühaufklärung (Frühe Neuzeit 37), Tübingen 1997, S. 51-77.

42 Vgl. J. F. Gerhard Goeters/Rudolf Mau (Hg.), Die Geschichte der Evangelischen Union, Bd. 1: Die Anfänge der Union unter landesherrlichem Kirchenregiment (18171850), Leipzig 1992, vgl. besonders S. 93-159.

43 Vgl. Jutta Kappel/Claudia Brink (Hg.), Mit Fortuna übers Meer. Sachsen und Dänemark - Ehen und Allianzen im Spiegel der Kunst (1548-1709), München 2009. Vgl. unter den dortigen Beiträgen besonders Ute Essegern, Kein Spielraum für Frauen? Hochzeitsverhandlungen und Heiratsverträge zwischen Sachsen und Dänemark in der Zeit von 1548 bis 1709, in: ebd., S. 55-61. Noch 1711 war eine Ehe zwischen dem späteren Friedrich August II. und einer dänischen Prinzessin im Gespräch (ebd., S. 60). Der Kurprinz trat jedoch kurze Zeit später zum Katholizismus über und heiratete 1719 die Kaisertochter Maria Josepha. 
Hohenzollern, ihren Hut in den Ring werfen. So erlangte Clemens Wenzeslaus, ein Sohn Friedrich Augusts II., den ganz sicher nicht unwichtigen Trierer Kurfürstenstuhl (1768). Eine seiner Schwestern, Maria Josepha, heiratete den Dauphin von Frankreich und wurde die Mutter der französischen Könige Ludwig XVI., Ludwig XVIII. und Karl X. Auf dem weiten Feld der Bildenden Künste, der Musik und teilweise der Literatur besaßen die katholischen Länder der Barockzeit eine dominierende Stellung innerhalb Europas: Man vergleiche Berlin unter dem Soldatenkönig und Wien unter dem gleichzeitig regierenden Karl VI. ${ }^{44}$ An diesem Kreis der kulturell führenden Territorien Europas nahm nun Sachsen zumindest partiellen Anteil. Wenn der Anschluss Brandenburg-Preußens an die Welt des westeuropäischen Calvinismus als entscheidender Schritt in Hinsicht auf den späteren Aufstieg des Landes zur deutschen Hegemonialmacht und zur europäischen Bedeutung gewertet wird, ist nicht ganz einsehbar, warum ein auf das katholische Europa gerichtetes ähnliches Agieren Sachsens ein leichtsinniger, dem heutigen und, so die unterschwellige Aussage, auch dem zeitgenössischen Beobachter sofort erkennbarer Fehler gewesen sein soll. Der Eintritt in die Welt der katholischen Mächte war der Versuch, in die Reihe derjenigen Potentaten einzurücken, die sozusagen am großen Rad zu drehen vermochten. Die Position als lutherische Führungsmacht war im Vergleich mit den sich jetzt öffnenden Möglichkeiten von eher nachgeordneter Bedeutung. ${ }^{45}$ Erst eine spätere Einschätzung, die die sogenannte deutsche Sendung des Hauses Hohenzollern in den Mittel- und Angelpunkt aller Beurteilung deutscher Geschichte zu stellen wusste, hat hier die Gewichte im historischen Rückblick anders tariert.

\section{Militär- oder Kulturstaat}

Nach Niebuhr kann ein Deutscher, der sich mit den Waffen auszeichnen will, dies nur in Preußen verwirklichen. Bezeichnend ist sein Hinweis auf die Sachsen Leibniz, Lessing und Luther, die wohl, heißt es gönnerhaft, zu ehren seien. Die Preu-

44 Zur Kulturgeschichte Wiens unter Karl VI. vgl. Karl Eduard Schimmer, Alt und Neu Wien. Geschichte der österreichischen Kaiserstadt, Bd. 2, Wien/Leipzig 1904, S. 111216. Allein die Personalkosten der Hofkapelle betrugen pro Jahr 200.000 Gulden (vgl. ebd., S. 169), eine geradezu exorbitante Summe. Neben dem Kaiserhof war Prinz Eugen als außerordentlich engagierter Förderer der Künste und Wissenschaften tätig. Vgl. Karl Gutkas (Hg.), Prinz Eugen und das barocke Österreich. Ausstellung der Republik Österreich und des Landes Niederösterreich. Marchfeldschlösser Schlosshof und Niederweisen, 22. April bis 26. Oktober 1986, Wien 1986.

45 Die Behauptung von Karlheinz Blaschke, der „politisch kurzsichtige Kurfürst“ habe bei seinem Übertritt zum Katholizismus „nicht bedacht“, dass er dadurch Sachsens Stellung als Vorsitz im Corpus Evangelicorum des Reichstages aufs Spiel setzt, ist wenig wahrscheinlich. Über einige Grundkenntnisse der Reichsverfassung dürften Friedrich August und seine Berater verfügt haben. Vgl. Karlheinz Blaschke, Der Konfessionswechsel des sächsischen Kurfürsten Friedrich Augusts II. und seine Folgen, in: Sachsen und Polen (wie Anm. 18), S. 210-222, hier S. 219. 
ßen aber könnten auf andere Persönlichkeiten stolz sein - das seien diejenigen, an deren Ruhm die sächsischen Jünglinge Anteil nehmen könnten, wenn sie künftig unter den Fahnen der preußischen Regimenter fechten dürfen. ${ }^{46}$ Es sind also große Feldherren und Schlachtenlenker. Der Ausbau Preußens zum Militärstaat, der in der Regierungszeit des Großen Kurfürsten einsetzte und unter Friedrich II. seinen Höhepunkt erreichte, ist sicher derjenige Wesenszug dieses Staates, der bis heute sein Bild am nachhaltigsten geprägt hat. Für Friedrich II. ist erklärtermaßen keine Kunst schöner und nützlicher als die des Krieges, denn diese vor allem verspricht Ehre, Ruhm und das Wohl des Vaterlandes. ${ }^{47}$ Das gilt aber wohl mehr für den (in Preußen fast durchweg adligen) Offizier, denn den „einfachen Mann“ (Vulgaire), heißt es an anderer Stelle des eben zitierten Testaments, treibe nur die Furcht vor seinem Offizier in die Schlacht. ${ }^{48}$ In den Befreiungskriegen kommt es bekanntlich $\mathrm{zu}$ einer gewissen, letztendlich aber wieder vorübergehenden Demokratisierung des Heeres, und Ehre kann nun auch der einfache Soldat erringen, z. B. in Gestalt des 1813 kreierten Eisernen Kreuzes. ${ }^{49}$ Was aber auch weiterhin als Staatsdoktrin bleibt, das ist der Kult des Militärischen. Der preußische Staat steht und fällt nach dieser Sichtweise mit seiner Armee. Noch einmal sei Niebuhr zitiert: „Die Blüte und der Kern unsrer Nation ist unser Heer; und seine innere Gesundheit und Vortrefflichkeit, wie sie für das Volk zeugt, aus dem sie hervorgegangen ist, wirkt wieder zurück auf die Nation und auf das jugendliche Geschlecht, welches sich unter den Fahnen bilden wird, Kräftigung und Reinigung immer weiter zu verbreiten. “50 Gewiss ist dieses Bramarbasieren nicht unbedingt mit einer ständig akuten Kriegsbereitschaft gleichzusetzen, aber es wirft ein bezeichnendes Licht auf das Selbstverständnis des preußischen Staates.

Dass in Sachsen das Militärwesen zu wenig Aufmerksamkeit gefunden habe, in finanzieller Hinsicht dürftig ausgestattet wurde usw., bildet eine gängige Kritik vieler Historiker. Die Existenz einer starken, allzeit zum Schlagen bereiten Armee bilde aber die wichtigste Grundlage des modernen Staates. Das Schwinden des politischen Gewichts Sachsens wird daher zuerst und vor allem auf seine militärische Schwäche zurückgeführt, ${ }^{51}$ ungeachtet der Tatsache, dass die sächsische Mili-

46 Niebuhr, Preußens Recht (wie Anm. 1), S. 51.

47 Vgl. Dietrich, Die politischen Testamente (wie Anm. 38), S. 556 f.

48 Vgl. ebd., S. $532 \mathrm{f}$.

49 Vgl. zuletzt Frank Wernitz, „Der Soldat mit dem Generale ganz gleich;...“. Ein Beitrag zur Entstehungsgeschichte des Eisernen Kreuzes, in: Gerhard Bauer/Gorch Pieken/Matthias Rogg (Hg.), Blutige Romantik. 200 Jahre Befreiungskriege, Bd. 2: Essays (Forum MHM 4), Dresden 2013, S. 122-129. Der Beitrag geht auch auf den zähen Widerstand ein, den die adligen Offiziere gegen die Einführung dieses Ordens leisteten.

50 Niebuhr, Preußens Recht (wie Anm. 1), S. 51.

51 Karl Czok/Reiner Gross, Das Kurfürstentum, die sächsisch-polnische Union und die Staatsreform, in: Karl Czok (Hg.), Geschichte Sachsens, Weimar 1989, S. 208-296, hier S. 283. Hanke, Zur Beurteilung (wie Anm. 17), S. 239 f. Hanke verweist auf bereits zeitgenössische Kritik an der Vernachlässigung der Militärausgaben zugunsten der Hoffestlichkeiten. 
tärgeschichte so ruhmlos nicht ist, wie unterschwellig suggeriert wird. Die Ursache des finanziell verursachten Ungenügens der militärischen Schlagkraft Sachsens ist dann rasch gefunden - es ist die hemmungslose Verschwendung, die am Hofe herrschte. Dafür ist in der ersten Hälfte der polnisch-sächsischen Union der König/Kurfürst August der Hauptverantwortliche, für die Regierungszeit seines Sohnes gilt der Premierminister Graf Heinrich von Brühl als Sündenbock. ${ }^{52} \mathrm{Ihm}$ wird zuerst und vor allem die militärische Schwächung Sachsens zugeschrieben. Ich erspare mir hier einschlägige Zitate, die über alle Zeiten hinweg die angeblich nur als betrüblich zu kennzeichnenden Zustände in Dresden vor allem unter August dem Starken mit den heftigsten Klagen und Anklagen in flammenden Farben an die Wand malen. Zitieren möchte ich stattdessen nur den dazu formulierten ironischen Kommentar Franz Mehrings in seiner stellenweise durchaus anregenden „Lessing-Legende“: „Allen Respekt vor der sittlichen Entrüstung über die Verschwendung der sächsischen Auguste, aber die Wohlfeilheit hat auch nie zu den Tugenden des preußischen Militarismus gehört, und vielleicht ist die Dresdener Gemäldegalerie ein ebenso wirksamer Hebel deutscher Kultur gewesen wie der Stock, mit dem die preußischen Friedriche ihre Soldaten drillten. “53

Die Militarisierung des gesamten gesellschaftlichen Lebens in Preußen ist ein zu gut bekanntes Phänomen, als dass es hier näher beschrieben werden muss. Nach einem immer wieder zitierten Bonmot des Militärtheoretikers Georg Heinrich von Berenhorst ${ }^{54}$ hat sich hier entgegen der ansonsten umgekehrten Praxis eine Armee einen Staat gehalten. Dementsprechend bildete die Armee Zentrum und Sinn des Staates: In jedem übrigen Verbältnisse zu den anderen Ständen des Staates war der Soldatenstand der geebrteste [...]. Alles dies vereinbart, gab dem Heere ein so eigenen Sinn und Dünkel, als seit Sparta und Rom, bey keinem Kriegsvolke wieder da gewesen war. ${ }^{55}$ Nach Friedrichs II. Auffassung muss der Herrscher Preußens ein Soldat sein, sonst geht mit Sicherheit über kurz oder lang

52 Vgl. zu Brühl zuletzt: Friedrich der Große und Graf Brühl. Geschichte einer Feindschaft, Begleitband zur ersten gemeinsamen Verbundausstellung, hrsg. von der Stiftung Fürst-Pückler-Museum - Park und Schloss Branitz, Cottbus 2012; Dresdener Kunstblätter 58 (2014), Heft 2: Heinrich von Brühl; Ute Christina Koch, Eine öffentliche Feindschaft. König Friedrich II. von Preußen und Heinrich Graf von Brühl in zeitgenössischen Publikationen, in: Preußen und Sachsen (wie Anm. 10), S. 252-259. Die Erarbeitung einer modernen Brühl-Biografie stellt ein dringendes Desiderat der Forschung dar. Das in der Tradition Friedrichs II. in der wissenschaftlichen und populären Geschichtsschreibung ganz und gar negativ eingefärbte Bild des Grafen dürfte dadurch wahrscheinlich eine Aufhellung erfahren. Vgl. auch im vorliegenden Band des NASG den Beitrag von Jürgen LuH, Feinde fürs Leben. Friedrich der Große und Heinrich von Brühl.

53 Franz Mehring, Gesammelte Schriften, Bd. 9: Die Lessing-Legende, hrsg. von Thomas Höhle/Hans Koch/Josef Schleifstein, Berlin 1963 [Erstveröffentlichung 1893], S. $216 \mathrm{f}$.

54 Georg Heinrich von Berenhorst, Aus dem Nachlasse, hrsg. von Eduard von Bülow, Dessau 1845, S. 187.

55 Ders., Betrachtungen über die Kriegskunst, über Ihre Fortschritte, ihre Wiedersprüche und ihre Zuverlässigkeit, 1. Abteilung, Leipzig 21798, S. 125. 
sein Staat zugrunde, denn dieser sei allenthalben von Feinden umstellt..56 So waren denn Staat und Wirtschaft ganz und gar auf die Befriedigung der Bedürfnisse des Militärs ausgerichtet. Reformen im Bereich des Staates und der Gesellschaft, die Preußen umso nötiger hatte, je weiter das 18. Jahrhundert voranschritt, bildeten Tabuthemen, wenn man dadurch eine Schwächung der Armee als Ergebnis fürchtete. ${ }^{57}$ Dabei hat König Friedrichs Argument, sein Land müsse seiner vielen Feinde wegen aufs äußerste gerüstet sein, bis heute als schlagende Begründung für die Militarisierung Preußens gedient. ${ }^{58}$ Es ist aber erst die vom König betriebene Politik des Vabanque, die Misstrauen und Furcht der Nachbarn erweckten. In Sachsen hat dagegen das Militärische, d. h. der alles andere in den Schatten stellende Dienst mit der Waffe nie eine solche Bedeutung wie in Preußen erlangt. Es gab die Armee, aber sie nahm im Staate keine Sonderstellung ein, der Soldat bzw. der Offizier bildete keinen absolut herausgehobenen Stand..$^{59}$ Als Friedrich Wilhelm I. 1728 Dresden besuchte, nahm er bezeichnenderweise daran Anstoß, dass die dortigen Offiziere aber sebr Babr gehalten werden denn sie mit die Laqueien Paradiren und nicht estimiret werden.60 In Sachsen musste man eben nicht unbedingt eine Uniform anlegen, um estimiret zu werden. Die Ausübung von Kunst

56 Vgl. Dietrich, Die politischen Testamente (wie Anm. 38), S. 622.

57 Auch dieses sehr komplexe Thema kann an dieser Stelle nur angesprochen werden. Vgl. zum „Heer als hemmenden Faktor“ Gordon A. Craig, Die preußisch-deutsche Armee 1640-1945. Staat im Staate, Königstein/Ts. 1980 [deutsche Erstausgabe Düsseldorf 1960], S. 32-40.

58 Vgl. neuerdings Ulrich Schlie, Das Duell. Der Kampf zwischen Habsburg und Preußen um Deutschland, Berlin 2013. Friedrich habe nur aus „strategischen Gründen“ Kriege geführt: „Doch wer die Lebensgesetze Preußens, seine damalige prekäre Situation betrachtet, der konnte keine andere Schlussfolgerung ziehen." (ebd., S. 110). Preußen verdanke allein seiner militärischen Stärke die Behauptung „gegen eine Übermacht von Feinden“; es sei also immer um eine „Macht der Gegenwehr“ gegangen (ebd., S. 31). Es fragt sich freilich, wie es zu einer solchen feindlichen Übermacht gekommen ist. Auch möchte man zweifeln, ob das preußische Militär immer nur eine „Macht der Gegenwehr“ gebildet hat. Die Behauptung, das „Militärische“ sei in Preußen zum „Paradigma“ geworden, das auch in den „dunkelsten Stunden“ zum Widerstand ermutigt habe, was auf den 20. Juli 1944 zielt, ist doch sehr fragwürdig. Ohne die preußischen Eliten, an deren vordersten Stelle das Militär stand, wäre es gar nicht zu der Situation gekommen, die einen 20. Juli erforderte.

59 Vgl. Reinhold Müller, Die Armee Augusts des Starken. Das sächsische Heer von 1730 bis 1733, Berlin 1984.

60 Отto Krauske (Bearb.), Die Briefe König Friedrich Wilhelms I. an den Fürsten Leopold zu Anhalt-Dessau 1704-1740, Berlin 1905, S. 391. Die gleiche, aber noch schärfer formulierte Kritik hatte der König schon Jahre zuvor am Hof in Hannover geübt (ebd., S. 162). - In der Mitte des 18. Jahrhunderts gehörten $20 \%$ der Berliner Bevölkerung dem Militärapparat an. Das bedeutete, dass ca. 16.000 Soldaten in der Stadt lebten und zwar in der Regel in den Haushalten der Berliner Bürger. Das Wirtschaftsleben der Hauptstadt stagnierte zeitweise, da die Handwerker aus Furcht vor den Werbeoffizieren scharenweise die Stadt verließen. Vgl. Peter-Michael Hahn, Berlin und Potsdam, in: Wolfgang Adam/Siegrid Westphal (Hg.), Handbuch kultureller Zentren der Frühen Neuzeit. Städte und Residenzen im alten deutschen Sprachraum, Bd. 1: Augsburg-Gottorf, Berlin/Boston 2012, S. 133-195, hier S. 148 f. 
und Wissenschaft galt gleichermaßen oder noch mehr als Möglichkeit, um gesellschaftliche Anerkennung zu finden. Das ist keine aus heutiger Betrachtungsweise zurückprojizierte Auffassung, sondern eine auch von Zeitgenossen vertretene Sicht. Genannt sei allein das Beispiel des dichtenden preußischen Soldaten Johann Friedrich von Wascheta. Der schreibt an den in Leipzig lebenden Ostpreußen Johann Christian Gottsched: $O$ wie beneyd ich euch anitzt/ Ibr Hirten an dem Pleißen Strande/ Die ibr in solcher Rube sitzt/ Als wie ich in unrubgem Stande./ Was hat denjengen doch bethört/ Der Edelleuten weis gemachet/ Daß nur wo man Trummeln hört/ Wo Bley und Polver blitzt und krachet/ Die Ehren-Pforte offen sey/ [...] Ich tadle Krieg und Waffen nicht/ Jedoch bekenn ich auch dagegen/ Daß derer Wißenschafften Licht/ Mebr gilt als gewetzter Degen/ Und daß das Gold der Wißenschafft/ Auch selbsten denen Edelleuten/Durch eine gantz besondre Krafft/ kan einen echten Rubm bereiten./ Ich wiederbole noch einmal/ Daß ich deßwegen euch beneide/ Die ibr durch eine kluge Wabl/ In Büchern sucht der Seelen Weide. ${ }^{61}$ Als Wascheta seinen Brief verfasste, war unter der Regierung des eher friedfertigen Friedrich Wilhelms I. das Blitzen von Pulver und Blei im realen Kampf noch mehr eine Sache der Fantasie. Wenige Jahre später wurde daraus Ernst. Die Verluste, die die Kriege Friedrichs II. forderten, sind für die damalige Zeit als exorbitant zu werten. Die Schlachten des Königs wurden unter rücksichtslosem Einsatz des gesamten „Menschenmaterials“ geführt, sodass selbst bei Siegen die Verluste mitunter höher waren als die des geschlagenen Gegners. Schließlich konnte die einmal erlangte Großmachtstellung, zu der Preußen eigentlich die Voraussetzungen fehlten, nur durch die Militarisierung des Staates in Permanenz gesichert werden und das auch nur scheinbar. 1806/07 erfolgte der Zusammenbruch des gesamten Systems. ${ }^{62}$

In Sachsen, wie eben schon erwähnt, bildete das Heer nicht „Blüte und Kern“ (Niebuhr) der Nation. Dass das Land dagegen einen Hort der Künste und Wissenschaften darstellte, war schon den Zeitgenossen geläufig. Als Symbolgestalt sei auf Johann Joachim Winckelmann verwiesen, der seine Jugend in Preußen immer als wahres Martyrium in der Erinnerung verwahrt hat ${ }^{63}$ und seinen Wechsel nach

61 Johann Christoph GotTsched, Briefwechsel unter Einschluß des Briefwechsels von Luise Adelgunde Victorie Gottsched, Bd. 4: 1736-1737, hrsg. von Detlef Döring/ Rüdiger Otto/Michael Schlott unter Mitarbeit von Franziska Menzel, Berlin/New York 2010, S. 40-43, hier S. 42 f.

62 Der hätte auch bereits im Siebenjährigen Krieg erfolgen können. Das Überleben Friedrichs II. sicherten allein der fehlende Zusammenhalt zwischen seinen Gegnern, die ihre Vorteile nicht zu nutzen wussten, und der pure Zufall (der Tod der russischen Zarin Elisabeth). Am Ende war auf preußischer Seite alles ein Vabanquespiel, das die borussische Geschichtsschreibung zur genialen Strategie des Königs uminterpretierte.

63 Die aus seinen Jugenderlebnissen resultierende Verachtung Preußens ist bei Winckelmann immer lebendig geblieben, z. B.: Es schaudert mich die Haut vom Haupt bis zu den Zehen, wenn ich an den Preußischen Despotismus und an den Schinder der Völker gedenke, welcher [das] von der Natur selbst vermaledeyete und mit Libyschen Sande bedeckte Land zum Abscheu der Menschbeit machen und mit ewigem Fluche belegen wird. Brief an Leonhard Usteri, 15. Januar 1763, zitiert nach JoHANN JoACHIM 
Dresden als einen großen Befreiungsschlag empfand. Sachsen hat er hinfort als sein Vaterland empfunden, denn hier sei der gute Geschmack der alten Griechen wieder auferstanden: Und man muß gestehen, dass die Regierung des grossen Angusts der eigentliche glückliche Zeit-Punct ist, in welchem die Künste, als eine fremde Colonie, in Sachsen eingeführet worden. Unter seinem Nachfolger, dem deutschen Titus, sind dieselben diesem Lande eigen worden, und durch sie wird der gute Geschmack allgemein. ${ }^{64}$ Tatsächlich waren August der Starke und sein Sohn exzellente Kenner und entsprechende Förderer der Kunst gewesen. In Dresden, schreibt der Winckelmann-Biograf Carl Justi, habe ein ungemeiner Kunstenthusiasmus geherrscht, der in den Fürsten seinen Rückhalt besaß: „Während August III. alsbald Zeichen der Langeweile von sich gab, wenn man ihm von Geschäften und Politik unterhielt: so erheiterten sich seine Züge, und seine Sprache wurde lebhafter, wenn das neueste Gemälde oder die letzte Oper oder die letzte Sauhatze aufs Tapet gebracht wurde." 65 Eine Förderung der Künste hatte es in Preußen noch unter Friedrich III. (I.) gegeben, dann kamen dunkle Zeiten für die Musen. Im Hofrangreglement dominierten Militärangehörige in geradezu augenscheinlicher Zahl. Gelehrte und Kunstschaffende waren bestenfalls auf den untersten Rängen zu finden, denn über die Stellung innerhalb der gesellschaftlichen Hierarchie entschied zuerst der militärische Rang. ${ }^{66}$

Sachsens Beiträge zur Kunst und Kultur sind äußerst weitläufig und können an dieser Stelle nicht einmal aufgezählt werden. Ein Beispiel, das den Kontrast zwi-

Winckelmann, Briefe, Bd. 2: 1759-1763, hrsg. von Walther Rehm in Verbindung mit Hans Diepolder, Berlin 1954, S. 283.

Johann Joachim Winckelmann, Gedanken über die Nachahmung der Griechischen Wercke in der Mahlerey und Bildhauer-Kunst [Erstausgabe 1755], in: Ders., Kleine Schriften, Vorreden, Entwürfe, hrsg. von Walther Rehm, Berlin/New York 22002, S. 27-59, hier S. 29.

65 Carl Justi, Winckelmann und seine Zeitgenossen, Bd.1: Winckelmann in Deutschland, Leipzig ${ }^{4} 1943$, S. 279.

66 Vgl. HAhn, Berlin und Potsdam (wie Anm. 60), S. 146. Unter Friedrich II. änderten sich die Verhältnisse, und man kann dem König die Förderung der Künste nicht abstreiten. Das in Sachsen herrschende Niveau wurde dennoch bei weitem nicht erreicht. Vgl. UTE Christina Koch, Potsdam contra Dresden. Die Kunstsammler Friedrich II. und Graf Brühl, in: Friedrich der Große und Graf Brühl (wie Anm. 52), S. 63-74. Zum begrenzten Kunstgeschmack des Königs vgl. auch Helmut Börsch-Supan, Die Kunst in Brandenburg-Preußen. Ihre Geschichte von der Renaissance bis zum Biedermeier dargestellt am Kunstbesitz der Berliner Schlösser, Berlin 1980, S. 118 f. Auch unter Friedrich II. hätten die Berliner Kunstsammlungen mit den Dresdnern nicht konkurrieren können. $\mathrm{Zu}$ beachten ist schließlich, dass die preußischen Herrscher im Gegensatz zu den Dresdner Kurfürsten und Königen über keinerlei persönliche Eindrücke von den westund südeuropäischen Kulturzentren verfügten. Vgl. zuletzt Helmut Börsch-Supan, Bildnismalerei in Brandenburg und Sachsen im 17. und 18. Jahrhundert, in: Preußen und Sachsen (wie Anm. 10), S. 336-343. Über die Zeit Friedrich Wilhelms I. heißt es dort (S. 341): „Militärisches drang in das gesamte Kulturleben ein und gab ihm einen freudlosen Anstrich“. 
schen Preußen und Sachsen gut erkennen lässt, möge genügen. ${ }^{67}$ Das deutsche Theater verdankt dem Brandenburg-Preußen der Frühen Neuzeit nur wenig. Der Pietismus war durchweg und ganz und gar theaterfeindlich. Unter Friedrich Wilhelm I. wurde diese Haltung Staatsprinzip. In der Instruktion des Königs für seinen Nachfolger heißt es in hinreichender Klarheit: Mein lieber Successor mus auch nicht zugebben das in seine Lender und Prowincen keine Komedien, Operas, Ballettes, Masckerabden, Redutten gehalten werden und ein greuel davor haben, weill es Gottlohse und Teuffelichts ist [...]. ${ }^{68}$ So war denn in der Universitätsstadt Halle die Existenz von Bühnen schlichtweg verboten. Das nächste erreichbare Theater befand sich in Lauchstädt, also auf kursächsischem Boden, und dorthin strömten die Hallenser bei allen hier zu erlebenden Aufführungen. In Berlin änderten sich nach dem Regierungsantritt Friedrichs II. die Verhältnisse, man denke nur an den Bau der Oper in den Vierzigerjahren, aber das kam, soweit der Hof eine Rolle spielte, kaum dem deutschen Theater zugute; erst in der zweiten Hälfte des 18. Jahrhunderts gewinnt Berlin in dieser Beziehung an Bedeutung. ${ }^{69}$ Leipzig dagegen ist durch Gottsched und die Neuberin eine der Geburtsstätten des neuen deutschen Theaters geworden, wie es in seinen wesentlichen Zügen bis heute existiert. Das kam nicht von ungefähr, sondern hat die Existenz eines starken und vor allem kulturell interessierten Bürgertums zum Hintergrund, das es zu dieser Zeit und diesem Maße in Berlin nicht gab. Trotzdem ist auch der Dresdner Hof wenigstens zu erwähnen, dem schon der alljährlichen Messen wegen die Existenz von Bühnen wichtig war und der darum diesen Entwicklungen wenigstens wohlwollend gegenüberstand. Dresden wiederum war in dieser Zeit einer der europäischen Mittelpunkte der Operngeschichte, es genügt der Verweis auf die Namen von Johann Adolf Hasse und seiner Frau Faustina Bordoni. Im Preußen des Soldatenkönigs besaß zu dieser Zeit allein die Marschmusik Geltung. ${ }^{70}$

67 Eine in die Wolle gefärbte borussische Geschichtsschreibung muss natürlich auch die Überlegenheit Preußens auf dem Gebiet der Künste verfechten. Sachsen ist dann Statthalter des mit Ablehnung betrachteten französischen Barock, während von Brandenburg aus „eine würdigere und ernstere Kunst, ein veredelter Geschmack verbreitet“ wurde. Die „Wucht“ dieser Kunst sei das Gegenteil „des verschnörkelten Barock“ in Dresden. Rudolf Quanter, Kulturgeschichte des deutschen Volkes, Stuttgart ${ }^{4}$ o. J., S. $558 \mathrm{f}$.

68 Dietrich, Die politischen Testamente (wie Anm. 38), S. 222. Vgl. auch Wolfgang Martens, Officinia Diaboli. Das Theater im Visier des halleschen Pietismus, in: Norbert Hinske (Hg.), Halle. Aufklärung und Pietismus (Zentren der Aufklärung 1; Wolfenbütteler Studien zur Aufklärung 15), Heidelberg 1989, S. 183-208.

69 Vgl. Ruth Freydank, Theater in Berlin. Von den Anfängen bis 1945, Berlin 1988. Friedrich II. förderte zwar Theater und Oper, aber seine Bemühungen galten ausschließlich französischen Schauspielergruppen bzw. der italienischen Oper. Das war freilich auch an anderen Höfen der Fall. 


\section{Absolutismus oder Ständestaat}

Die Überlegenheit Preußens lag nach Niebuhr nicht zuletzt auch in seinem Sachsen gegenüber überlegenen Verwaltungsapparat und seiner fortschrittlichen Staatsverfassung. Auch dieses Argument findet sich bei späteren Historikern wieder, mit besonderer Prägnanz bei Treitschke: Sachsen sei noch zu Beginn des 19. Jahrhunderts ,in einer veralteten Gesellschaftsordnung “ verharrt, die Preußen bereits unter dem Großen Kurfürsten überwunden habe, um sich in ein „modernes Gemeinwesen“ zu verwandeln, in dem die „lebendige monarchische Gewalt" über alle sozialen Gegensätze gewaltet habe. ${ }^{71}$ Knapp ein halbes Jahrhundert später gelangt Haake in seinem Vergleich zwischen Brandenburg und Sachsen zu einem ähnlichen Ergebnis: „Aber das Entscheidende ist und bleibt: zu gesunder Kraft eines einheitlichen politischen Organismus, zu einem im Wettstreit und Lebenskampf vorankommenden Machtstaate konnte in dem sich mehr und mehr zersetzenden deutschen Reiche nur die absolute Monarchie führen. “72 Dass die absolute Monarchie bzw. die Regierungsform des Absolutismus in Deutschland fast flächendeckend triumphierte, bildet nun die allgemeine Auffassung der älteren Forschung. ${ }^{73}$ Indem Sachsen entgegen diesem die Entwicklung dominierenden Trend weiterhin „in altständischen Formen verharrte“ und so in seinem „innern politischen Leben" in Stillstand stagnierte, sei es Brandenburg gegenüber in einen entscheidenden Nachteil geraten. ${ }^{74}$ Diesen Stillstand erkennt der eben zitierte Otto Kaemmel im Unvermögen, die staatlichen Kräfte in den Händen des Herrschers zusammenzufassen und in dem bleibenden oder gar anwachsenden Einfluss der Stände. Dass dagegen unter dem Großen Kurfürsten die Macht der Stände in den verschiedenen preußischen Territorien gebrochen worden sei, wird als schlechthinnige Voraussetzung für die Entfaltung des Machtstaates Preußen betrachtet. Das betrifft alle Lebensbereiche, z. B. auch die Wirtschaft. Die sächsische Volkswirtschaft hätte nur dann „förderlich gedeihen können, wenn ihr nicht die Interessen der Stände hemmend im Wege“ gestanden hätten. Geschehen konnte

71 Treitschke, Deutsche Geschichte (wie Anm. 11), S. 474.

72 HaAke, Kursachsen (wie Anm. 11), S. 215.

73 Vgl. z. B. Hajo Holborn, Deutsche Geschichte in der Neuzeit, Bd. 1: Das Zeitalter der Reformation und des Absolutismus (bis 1790), Frankfurt a. M. 1981 [englische Erstausgabe 1959]: „überall in Deutschland gingen die Fürsten als absolute Herrscher hervor.“ (ebd., S. 390). Nach der Auffassung von Hans-Joachim Schoeps bildete der von Kurfürst Friedrich Wilhelm etablierte fürstliche Absolutismus die „moderne Herrschaftsform“ („staatsbildende Idee des 17. Jahrhunderts“), die sich gegen „den landschaftlichen Sondergeist" richtete (Schoeps, Preussen (wie Anm. 28), S. 33). Noch 1999 heißt es in einem handbuchartigen Werk von Wolfgang Reinhard, die Stände hätten der „weiteren Staatsbildung im Wege“ gestanden und mussten daher „verschwinden“. Das Ständewesen sei folgerichtig in Europa „weithin beseitigt“ worden („Zeit des Ständesterbens"). Vgl. Wolfgang ReInHaRd, Geschichte der Staatsgewalt. Eine vergleichende Verfassungsgeschichte Europas von den Anfängen bis zur Gegenwart, München 1999, S. 223, 234.

74 Otto Kaemmel, Sächsische Geschichte, Leipzig 1905, S. 97, 99. 
das aber nur, weil die „schwache fürstliche Willensvertretung“ den Ständen nicht entgegentrat, im Gegensatz zu dem „arbeitsamen, kühnen und weitblickenden“ Großen Kurfürsten. ${ }^{75}$ In der einhundert Jahre nach Kaemmels Buch erschienenen „Landesgeschichte Sachsens“ von Katrin Keller lautet das Urteil über die verhängnisvolle Rolle der Stände immer noch ähnlich: Sachsen verlor seit der zweiten Hälfte des 17. Jahrhunderts gegenüber den „fortgeschrittenen“ Territorien des Reiches (man wird hier an Brandenburg denken dürfen) laufend an Boden, da es nicht gelang, die Macht der (vom Adel dominierten) Stände zu beschränken. Das habe, in Verbindung mit der auch hier wieder beklagten verderblichen Politik Brühls, zum Niedergang Sachsens schon vor der Katastrophe des Siebenjährigen Krieges geführt. ${ }^{76}$

An dem eben grob skizzierten Bild lässt sich vielfältige, hier wiederum nur anzudeutende Kritik äußern. Von einer straff zentralistisch geführten, alle Landesteile nach einheitlichen Normen organisierende Regierung kann bei keinem der Territorien des Alten Reiches die Rede sein. Das gilt ebenso für Preußen ${ }^{77}$ und zwar auch für die Regierungszeit Friedrichs II., der nur bedingt Anstrengungen zur Integration seiner verschiedenen Länder unternahm. ${ }^{78}$ Auch ist zu beachten, dass Brandenburg-Preußen bis zum Ende des Reiches (1806) ein Stand dieses Staatsgebildes geblieben ist, auch wenn die Historiografie stillschweigend den Eindruck vermittelt, als sei der Preußenkönig so etwas wie ein auswärtiger Monarch gewesen, dem die Organe des Reiches gleichgültig sein konnten. Souverän war der Preußenherrscher in Bezug auf das eigentliche Königreich Preußen (Ostpreußen), nicht aber in seinen zum Reich gehörenden Territorien; ${ }^{79}$ dort war er und blieb er ein Kurfürst. Als ein Mythos ist schließlich die Behauptung von der gänzlichen Entmachtung der Stände zu werten. Im Zusammenhang mit der schon seit mehreren Jahrzehnten diskutierten Kritik am Begriff des Absolutismus ${ }^{80}$ wird

75 Kötzschke/Kretzschmar, Sächsische Geschichte (wie Anm. 19), S. 256 f.

76 Vgl. Katrin Keller, Landesgeschichte Sachsen, Stuttgart 2002, S. 146-154, insbesondere S. 153. Die „politische Theorie der Frühen Neuzeit“ habe dagegen die Ausweitung der „persönlichen Machtausübung des Landesherrn“ gefordert (ebd., S. 147). Positiv wird vermerkt, dass Friedrich August II. zwischen 1749 und 1763 die Stände nicht einberufen hat (ebd., S. 153). Das wird aber nach 1756 aus naheliegenden Gründen gar nicht möglich gewesen sein. Ähnlich wird in folgender neueren, mehrfach verlegten Publikation geurteilt: Helmut Neuhaus, Friedrich August I., in: Frank-Lothar Kroll (Hg.), Die Herrscher Sachsens. Markgrafen, Kurfürsten, Könige 1089-1918, München 2004, S. 173-191. Als „besonders starker Herzog und Kurfürst“ sei Friedrich August nicht hervorgetreten, da er von seinen Landständen abhängig blieb - im Unterschied zum brandenburgischen Kurfürsten (ebd., S. 181, 184). Vgl. Clark, Preußen (wie Anm. 11), S. 141-143.

78 Vgl. ebd., S. 289 f.

79 So meint Axel Gotthard, Berlin habe sich kaum um die Reichsgerichte gekümmert, da man sich ihnen gegenüber souverän gefühlt habe. Vgl. Axel GotTHARD, Das Alte Reich 1495-1806, Darmstadt 2003, S. 125.

$80 \mathrm{Vgl}$. zu diesem weitläufigen Thema u. a. Peter Baumgart, Absolutismus ein Mythos? Aufgeklärter Absolutismus ein Widerspruch? Reflexionen zu einem kontroversen Thema gegenwärtiger Frühneuzeitforschung, in: Zeitschrift für Historische Forschung 27 (2000), S. 573-589. 
auch den nach Auffassung der älteren Forschung in die Bedeutungslosigkeit abgesunkenen Ständen wieder stärkere Beachtung geschenkt, sei es in Brandenburg oder in anderen Territorien. Bestimmte Rechte und Einflussmöglichkeiten blieben ihnen erhalten oder wurden von ihnen zumindest beansprucht und das keineswegs immer erfolglos. ${ }^{81}$ Zum anderen ist grundsätzlich zu fragen, ob die verbreitete Bewertung der Rolle der Stände als allein retardierender Faktor in der Entwicklung des modernen Staates der Wirklichkeit gerecht wird. Im Gegenteil lässt sich die These vertreten, dass die in weiten Teilen Europas verbreitete Ständeverfassung einen der Faktoren bildete, die die Herausbildung der Moderne in einem wesentlichen Maße förderten. Sicherlich sind die Landtage der Frühen Neuzeit nicht als unmittelbare Vorbilder oder Vorgänger der heutigen Volksvertretungen zu bezeichnen. Dennoch konnten durch ihre Existenz bestimmte zentrale Vorstellungen der späteren parlamentarisch organisierten Staaten sozusagen in die Welt eintreten: das Repräsentationsprinzip, Mitspracherecht an der Regierung, der Ansatz zur Trennung der Gewalten (Legislative, Exekutive, Justiz). ${ }^{82}$ Das sind Aspekte, die gegenüber der gängigen Kritik an der angeblichen Provinzialität der Stände ${ }^{83}$ wenigstens Beachtung finden sollten.

Vor dem Hintergrund der eben angeführten Bemerkungen ließe sich diskutieren, ob das Ausbleiben einer Beseitigung der Ständemacht in Sachsen tatsächlich von so eindeutig negativer Tragweite für die Herausbildung einer modernen Staatlichkeit gewesen ist, wie das in der älteren Historiografie immer wieder mit Selbstverständlichkeit konstatiert worden ist.

Neuere Arbeiten zeigen, dass die überkommene, fast nie hinterfragte Feststellung anzuzweifeln ist, die Stände hätten nur ihre partikularen Interessen verfolgt, ohne jede Rücksicht auf die Belange des Gemeinwohls. Die Stände blieben vielmehr ein aktives und bei allem Fortleben verschiedenster Sonderbestrebungen

81 Vgl. Wolfgang Neugebauer, Brandenburg im absolutistischen Staat. Das 17. und 18. Jahrhundert, in: Ingo Materns/Wolfgang Ribbe (Hg.), Brandenburgische Geschichte, Berlin 1995, S. 291-394, hier S. 325, 374-376. Nach Neugebauer kam es im Laufe des 18. Jahrhunderts sogar zu einer teilweisen Reaktivierung der Rechte der Stände.

82 Vgl. Michael Mitterauer, Warum Europa? Mittelalterliche Grundlagen eines Sonderwegs, München 2003, S. 109-151. Gegen die Auffassung, der die Ständegewalt niederringende Absolutismus sei eine notwendige Entwicklungsstufe in Richtung moderner Staat gewesen, wendet sich besonders vehement Günter Barudio. Als Gegenmodell setzt er eine libertäre Verfassung, die in der Existenz der Stände gegründet ist. Deren totale Ausschaltung in Preußen habe dieses Land zum Prototyp einer Despotie umgeformt. Dieses Urteil dürfte über das Ziel hinausschießen, bleibend aber ist die Kritik am Absolutismus preußischer Prägung als notwendiges Stadium der historischen Entwicklung. Vgl. Günter Barudio, Das Zeitalter des Absolutismus und der Aufklärung 1648-1779 (Fischer Weltgeschichte 25), Frankfurt a. M. 1981, zu BrandenburgPreußen vgl., S. 190-262.

83 Vgl. z. B. Gerhard Oestreich, Verfassungsgeschichte vom Ende des Mittelalters bis zum Ende des alten Reiches (Gebhardt Handbuch der deutschen Geschichte 11), München 61986. Dort heißt es dezidiert: Die „Voraussetzungen der modernen Staatsbildung“ wurden vom Großen Kurfürsten „gegen die provinzialen Interessen der Stände durchgesetzt." Ebd., S. 99 f. 
dennoch auch an der allgemeinen Landeswohlfahrt orientiertes Element des staatlichen Lebens. ${ }^{84}$ Eine nicht unbeträchtliche Rolle spielte dabei das Selbstverständnis der Stände, einen Schutzwall des Luthertums gegenüber allen Gefährdungen zu bilden, die von dem katholisch gewordenen Landesherrn ausgehen konnten. Das stellte kein Partikularinteresse dar, sondern war ein zentrales Anliegen aller kursächsischer Länder und aller ihrer Bevölkerungsschichten. ${ }^{85}$ In den sächsischen Nebenlanden, also vor allem in den beiden Lausitzen, scheinen die Spielräume der Stände noch größer gewesen zu sein als in den Erblanden. So waren in der Niederlausitz die Steuer- und Landesverwaltung, das Gesundheits-, Schulund Verkehrswesen weitgehend Angelegenheiten der Stände. Diese Entwicklung gewann im Laufe der Zeit noch an Dynamik, sodass für die Zeit des ausgehenden 18. Jahrhunderts von einem "frischen, verantwortungsbewußten Geist" gesprochen werden kann, der die Stände erfüllt hatte. Dagegen lässt sich eine weitgehende Zurückdrängung der Tätigkeit der Stände in der unmittelbar benachbarten Kurmark beobachten. ${ }^{86}$ Dass auch der Landtag der Erbländer mehr bedeutete als nur ein Gremium regionaler Interessenpolitik gilt noch für die Spätzeit des Alten Reiches. Der Landtag von 1793 bildete die Plattform einer vor dem Hintergrund der Französischen Revolution geführten regen Debatte über Grundfragen der sächsischen Verfassung. Die Auseinandersetzung fand in den Folgejahren ihre Fortsetzung und ist als „Broschürenstreit“ in die Geschichte eingegangen. ${ }^{87}$ Ausgangspunkt bildete die Forderung nach Abschaffung der Steuerfreiheit für Rittergüter, bald aber kamen auch mannigfache andere Fragen zur Sprache, z. B. die ungünstige Lage der Bauernschaft, religiöse Toleranz, fehlende Einheit des Staats-

84 Für das frühe 18. Jahrhundert vgl. vor allem die wichtige Arbeit von Wieland Held, Der Adel und August der Starke. Konflikt und Konfliktaustrag zwischen 1694 und 1707 in Kursachsen, Köln/Weimar/Wien 1999. Zusammenfassend formuliert der Autor prägnant: „Die Forschung wird, so scheint es, gut daran tun, wenn sie den Konfliktaustrag von Seiten der Stände nicht so sehr und vor allem nicht allein als Kampf zur Hinderung ihres Fürsten an der Ausweitung seiner potestas absoluta begreift, sondern mehr noch als Beitrag [...] zur Ausgestaltung der politischen Kultur sowie zur Hebung und Verbesserung der Landeswohlfahrt.“ (ebd., S. 246). Held kann seine These mit zahlreichen Beispielen belegen.

85 Vgl. dazu u. a. Karlheinz BlaschKe, Landstände, Landtag, Volksvertretung. 700 Jahre politische Mitbestimmung im Land Sachsen, in: Uwe Schirmer/André Thieme (Hg.), Beiträge zur Verfassungs- und Verwaltungsgeschichte Sachsens. Ausgewählte Aufsätze von Karlheinz Blaschke. Aus Anlaß seines 75. Geburtstages (Schriften zur sächsischen Geschichte und Volkskunde 5), Leipzig 2002, S. 229-254, hier S. 237.

86 Vgl. Rudolf Lehmann, Die Niederlausitzer Stände in sächsischer Zeit. Ein Beitrag zur Verfassungs- und Verwaltungsgeschichte der Niederlausitz, in: Helmut Lötzke/HansStephan Brather (Red.), Archivar und Historiker. Studien zur Archiv- und Geschichtswissenschaft. Zum 65. Geburtstag von Otto Meisner, hrsg. von der staatlichen Archivverwaltung im Staatssekretariat für Innere Angelegenheiten (Schriftenreihe der staatlichen Archivverwaltung 7), Berlin 1956, S. 308-325, hier S. 321.

87 Vgl. Axel Flügel, Bürgerliche Rittergüter. Sozialer Wandel und politische Reform in Kursachsen (1680-1844) (Bürgertum 16), Göttingen 2000, S. 180-187. Die einzige ausführlichere Abhandlung bildet jedoch weiterhin Wilhelm BeHREndTs, Reformbestrebungen in Kursachsen im Zeitalter der französischen Revolution, Leipzig 1914. 
gebietes, Patrimonialgerichtsbarkeit, Verminderung des Heeres, Schulreformen, Verbesserung der Justiz usw. Diese Hinweise sollen nicht den sächsischen Landtag zu einem Parlament modernen Zuschnittes stilisieren, aber doch belegen, dass Treitschkes Behauptung vom „altständischen Stilleben“ in Sachsen an der historischen Wirklichkeit einigermaßen vorbeigeht.

Nur am Rande sei das Thema innere Verwaltung berührt. Die borussische Geschichtsschreibung pflegt hier die Erzählung von Friedrich Wilhelm I. als „größten inneren König" Preußens. Die moderne Staatsverwaltung und der sie ausübende treue Beamte sind sein Werk und sein Verdienst. Nochmals sei Moeller van den Bruck zitiert, der mit markigen Worten nur das zusammenfasst, was opinio communis der zeitgenössischen Historiografie bildete: „Der Soldatenkönig stabilisierte die Pflicht als das Gebot aller Gebote in Preußen, wider das es keinen Einspruch gab: mit ihr verpflichtete er sich als preußischer König die preußischen Menschen, die wurden, wie er war - und mit diesen verpflichteten Menschen gelang ihm, die späteren Machtmittel des preußischen Staates, die preußische Armee und das preußische Beamtentum, so durchzubilden, daß sie, von ihm an, zur dauernden Grundlage der künftigen Entwicklung wurden." 88 Auch hier wiederum bietet Sachsen das Kontrastprogramm: Preußen verfügte, so Treitschke mit Blick auf die Verhältnisse im frühen 19. Jahrhundert, über alles das, was die Sachsen bitter vermissten: „eine gescheite, schlagfertige, bürgerfreundliche Verwaltung“, ein freies Städtewesen, Beseitigung aller Vetternwirtschaft usw. ${ }^{89} \mathrm{Die} \mathrm{Zu}$ stände in Sachsen können dann in der weiter zurückliegenden Zeit nur noch katastrophaler gewesen sein. Paul Haake vermittelt ein entsprechendes in kräftigsten Farben gepinseltes Gemälde von der „Lotter- und Gevatternwirtschaft“, der Unehrlichkeit der Beamten, was auf das Versagen des sittenlosen August zurückgeführt wird, der als „von Begierde zu Genuß taumelnder [...] sittlicher Schwächling“ im Gegensatz zum Preußenkönig anderen „kein Vorbild der Opferwilligkeit" bieten konnte. 90 Nun ist die Ausbildung einer modernen Bürokratie kein Spezifikum der preußischen Geschichte, sondern in der Frühen Neuzeit ein allge-

88 Moeller van den Bruck, Der preußische Stil (wie Anm. 13), S. 81. In der Sprache der akademischen Historiografie liest sich das so: Friedrich Wilhelm „ordnete und verstärkte“ die Behörden. „Und diesem neuaufgerichteten Organismus setzte er [...] seine Aufgaben, bestimmte das Verfahren, durchtränkte das Ganze mit seinem feurigen, gebieterischen sittlichen Ernst, mit dem kategorischen Imperativ seines Pflicht- und Staatsbewußtseins. Er gestaltete [...] dieses Beamtentum einheitlich aus: ein Beamtentum, das dem Könige, dem Staat dient [...]“. Vgl. Erich Marcks, Das Königtum der großen Hohenzollern, in: Ders., Männer und Zeiten. Aufsätze und Reden zur neueren Geschichte, Bd. 1, hrsg. von Gerta Andreas, Stuttgart/Berlin 71942, S. 145-182, hier S. 167. Marcks' Aufsatzsammlung erreichte über die zahlreichen Auflagen, die sie erlebte, eine breite Leserschaft. Transferiert wird das Bild des Historikers Marcks (und anderer Gelehrter) in die Belletristik durch Jochen Kleppers Roman „Der Vater“ (1937), der freilich auch vor dem Hintergrund seiner Entstehungszeit (Drittes Reich) gesehen werden muss. HaAke, August der Starke (wie Anm. 7), S. 72. 
meines, sich vor allem bei den größeren Reichsständen entwickelndes Phänomen. Die Rahmenbedingungen, unter denen sich diese Entwicklung vollzog, und die Ergebnisse, die sie zeitigte, sind nun so unterschiedlich nicht, wie das die überlieferte Apotheose des preußischen Beamten, der allen anderen Territorien ein Vorbild gewesen sein soll, suggerieren will. Gerade am Beispiel des preußischen Staates ist gezeigt worden, dass die moderne Bürokratie sich nicht als gänzlich neuartiges Phänomen entwickelte, sondern überall die Züge der altständischen Gesellschaft trug, d. h. Nepotismus, Vetternwirtschaft und das Verständnis eines Amtes als „Beute“ verschwanden keineswegs über Nacht. Das lässt sich in Sachsen so gut wie in Preußen beobachten. ${ }^{91}$

\section{Preußen und Sachsen als geistige Fübrungsmächte}

Niebuhrs Eloge auf das vorbildliche bildungs- und wissenschaftsfördernde Wirken des preußischen Staates, gesehen im Kontrast zur „Kargheit“ Sachsens auf diesen Gebieten, öffnet den Blick auf einen mit besonderer Intensität gepflegten Mythos der Geschichte Preußens. Danach ist die geistige Führung Deutschlands Ende des 17. Jahrhunderts unwiderruflich von Sachsen an Preußen übergegangen. Das konstatiert kein geringerer als Adolf von Harnack: „Dieser Staat, der durch den Großen Kurfürsten die Führung in Norddeutschland gewonnen hatte, erhielt unter seinem Nachfolger auch die geistige Führung. "92 Dies geschah sozusagen ganz äußerlich sichtbar im Ortswechsel der intellektuell führenden Köpfe der Zeit. Leibniz, Pufendorf, Thomasius, Spener und Francke, um nur sie zu nennen, verlassen das intellektuell verkümmernde Sachsen und stellen sich dem auch auf dem Gebiet der Wissenschaften dynamisch aufstrebenden Kurbrandenburg zur Verfügung. Ihr Wirken in der neuen Heimat dokumentiert sich u. a. in der Gründung der Berliner Akademie der Wissenschaften, in der Errichtung der Universität Halle, im Aufbau der Franckeschen Stiftungen. Letztere ist engstens verbunden mit der Ausbreitung des Pietismus als der großen religiösen Reformbewegung innerhalb des Luthertums. ${ }^{93}$ Daneben ist es der intellektuelle Einfluss der sich

91 Vgl. die grundlegende Untersuchung von Hans Rosenberg, Bureaucracy, Aristocracy and Autocracy. The Prussian Experience 1660-1815, Cambridge/Mass. 1966. Rosenberg betont den innovativen Charakter des modernen Verwaltungswesens, stellt dann aber fest: „But all these innovations or modifications proved compatible, in the world of facts, with favoritism and the persistence of the nepotist practices of hereditary officeholding." Viele der "neuen Bürokraten“ „were chosen not so much because they were able but because of their special connections with those who stood at the top or near the top of the hierarchy of ,commissars"“. So existiere im modernen Verwaltungsapparat keine feste Linie (fixed line) „,spoils‘ from ,merit““. Ebd., S. 87.

92 Adolf von Harnack, Das geistige und wissenschaftliche Leben in BrandenburgPreußen um das Jahr 1700, in: Büsch/Neugebauer (Hg.), Moderne Preußische Geschichte (wie Anm. 21), Bd. 3, S. 1243-1267, hier S. 1243.

93 Vgl. die klassische Studie von Carl Hinrichs, Preußentum und Pietismus. Der Pietismus in Brandenburg-Preußen als religiös-soziale Reformbewegung, Göttingen 1971. 
unter Förderung des calvinistischen Herrscherhauses vor allem in Berlin etablierenden hugenottischen Kolonie, der zum Aufstieg Preußens zu einem „Zentrum der geistigen Erneuerung“ beitrug. Wir kommen damit nochmals auf den bereits behandelten Konfessionswechsel der Hohenzollern zu sprechen. Für Heinz Schilling erscheint die von ihm geradezu mythisch überhöhte „preußische Weihnachtsgeschichte“, gemeint ist der Übertritt Kurfürst Johann Sigismunds zum Calvinismus am 25. Dezember 1613, überhaupt als wichtigster Schlüssel zur Erklärung des "Mirakels“ Brandenburg. Der von diesem Akt ausgehende Dynamisierungsschub erfasste fast alle Lebensbereiche, und insbesondere eben auch Bildung und Wissenschaft.

Das Kontrastbild liefert wiederum Kursachsen, dessen Anteil an der Bildungsund Wissenschaftsgeschichte Schilling eine ganze Zeile widmet; bei Preußen sind es 18 Seiten. Es genügt ihm die Mitteilung, dass die sächsischen Universitäten "theologisch und allgemein-wissenschaftlich in Orthodoxie erstarrt" waren, die neue Universität Halle dagegen sei weltoffen gewesen, d. h. aufs Praktische orientiert, lebensnah, weltlich ausgerichtet, undogmatisch. ${ }^{94}$ Das pejorativ belastete Stichwort Orthodoxie erscheint überhaupt bis in viele neuere Publikationen hinein als ein wahrer Gruselbegriff, der beschworen wird, um die absolute Ferne der solchermaßen charakterisierten Personenkreise von allen Tendenzen der Moderne in drastischer Form zu kennzeichnen. ${ }^{95}$ Ein „Orthodoxer" ist in dieser Optik anscheinend nichts anderes als ein Synonym für „Dunkelhut“. Frühe und äußerst erfolgreiche Herolde dieses Geschichtsbildes, oder besser gesagt Zerrbildes, waren der Frühaufklärer Christian Thomasius und der Pietist Gottfried Arnold, beide aus Sachsen stammend und beide schließlich in preußischen Diensten stehend.96 Ihr Bild der Orthodoxie ist sehr lange das beherrschende geblieben. Von dieser Warte aus versteht es sich von selbst, dass es sich über ein angeblich ganz von der lutherischen Orthodoxie geprägtes Land wenig zu berichten lohnt. Die große Heerstraße, auf der die geschichtliche Entwicklung einherschreitet, verläuft auf ganz anderem Gelände - eben im pietistisch geprägten Preußen.

Nun liegen auch hier die Dinge etwas anders. Die Beschäftigung mit den konkreten Erscheinungsformen der in sich sehr differenzierten Orthodoxie und vor allem mit ihren einzelnen Vertretern zeigt, dass ein scharfer Schnitt zwischen der Moderne und einer sich gegen sie wendenden bzw. abschottenden Rechtgläubigkeit nicht sinnvoll ist. Orthodoxie, Pietismus und Aufklärung bilden die wichtigs-

94 Schilling, Höfe und Allianzen (wie Anm. 22), S. 400. Schilling nennt nur die Universität Wittenberg, dürfte damit aber auch Leipzig als andere kursächsische Universität meinen.

95 So erscheint bei Katrin Keller der Dresdner Superintendent Valentin Ernst Löscher als "Personifizierung“ der Orthodoxie, die einen „kompromisslosen“ Kampf gegen Katholizismus, Pietismus und Aufklärung führt. Vgl. Keller, Landesgeschichte (wie Anm. 76), S. 177. Einem vielschichtigen Charakter, wie Löscher ihn verkörperte, werden solche globale Urteile nicht gerecht.

96 Vgl. Hans Leube, Die Reformideen in der deutschen lutherischen Kirche zur Zeit der Orthodoxie, Leipzig 1924, S. 17 f. 
ten das geistige Leben im Deutschland des späten 17. und des folgenden 18. Jahrhunderts bestimmenden Strömungen. Der Pietismus, die Aufklärung, die Orthodoxie stellen jedoch idealtypische Konstruktionen dar, die es in der historischen Wirklichkeit so kaum gegeben hat. Jene Phänomene waren in sich äußert vielgestaltig, und sie überschneiden, sie überlappen einander in mannigfachster Weise. Ein „Orthodoxer“ kann somit pietistisch eingefärbt sein, er kann aber auch von der Aufklärung beeinflusst werden. Das belegt, um nur ein Beispiel zu nennen, das Auftreten zahlreicher orthodoxer Theologen als erklärte Wolffianer. Der im ernestinischen Weimar lehrende Jakob Carpov ist einer der bekannteren Vertreter dieser Richtung. In Leipzig jedenfalls waren die orthodoxen Theologen anerkannte Mitglieder der Gelehrtengemeinschaft. Niemand wird bezweifeln, dass die gleich nochmals zu erwähnende Zeitschrift „Acta Eruditorum“ zur Geschichte der Aufklärung zu zählen ist. ${ }^{97}$ An deren Herausgabe waren die „Orthodoxen“ rege beteiligt, zu verschiedenen wissenschaftlichen Disziplinen schrieben sie maßgebende Werke, 98 ihre praktische Tätigkeit für Universität und Kirche lässt sich nicht auf die Kultivierung von dogmatischen Streitereien reduzieren.

Was nun die Aufklärung selbst betrifft, so vollzogen sich in Sachsen bereits im 17. Jahrhundert Entwicklungen, die in Brandenburg-Preußen zum Teil erst Jahre oder Jahrzehnte später in nennenswertem Umfange nachgeholt wurden. Vor diesem Hintergrund geht Harnacks Behauptung von der führenden intellektuellen Rolle, die Preußen um 1700 innerhalb Deutschlands ausgeübt haben soll, an der Wirklichkeit einigermaßen vorbei. Das kann hier nur kurz angedeutet werden. ${ }^{99}$ Von grundlegender Bedeutung war der Aufstieg Leipzigs zu einem der führenden europäischen Druckzentren noch im 15. Jahrhundert. In Berlin wurde weit später, nämlich 1539 die erste Druckerei eingerichtet, um auch bald schon wieder geschlossen zu werden. Das Leipziger Verlagswesen bildete, ohne damit die ganz erhebliche Bedeutung von Jena, Halle, Göttingen und dann auch Berlin unbeachtet lassen zu wollen, eine Voraussetzung für die Ausbreitung der deutschen Aufklärung. Das demonstriert schon die Entwicklung des Zeitschriftenwesens, dessen Ursprünge eben nicht in Berlin liegen, sondern in Leipzig. Die „Acta Eruditorum“ (ab 1682) als erstes Periodikum bildeten über lange Zeit das führende, ein internationales Ansehen genießende gelehrte Periodikum Deutschlands. Andere,

97 Vgl. Augustinus Hubertus Laeven, The „Acta Eruditorum“ under the editorship of Otto Mencke (1644-1707). The history of an international learned jornal between 1682 and 1707, Amsterdam/Maarssen 1990 [holländische Erstausgabe 1986].

98 Ich nenne als Beispiel nur den Leipziger Theologen und Pietistengegner Thomas Ittig, der eine der ersten umfassenden Darstellungen der Vulkankunde verfasste (THOMAS IтTIG, De montium incendiis, Leipzig 1671). Diesen Hinweis verdanke ich Herrn Dr. Konrad Lindner (Leipzig).

99 Vgl. den anlässlich der Jubiläumsausstellung „600 Jahre Universität Leipzig“ erschienenen zweibändigen Katalog Detlef Döring/Cecilie Hollberg (Hg.), Erleuchtung der Welt. Sachsen und der Beginn der modernen Wissenschaften, 2 Bde., Dresden 2009. Die Bände geben über die Stadt Leipzig hinaus einen umfassenden Überblick über die Aufklärungsbewegung in Sachsen. 
bald auch fachspezifisch ausgerichtete Zeitschriften folgten im frühen 18. Jahrhundert. Die Geschichte der gelehrten Sozietäten in Deutschland hebt nicht erst mit der Gründung der übrigens lange nur sehr unbefriedigend arbeitenden PreuBischen Akademie an, 100 sondern mit den wissenschaftlichen Gesellschaften, die sich ab der Mitte des 17. Jahrhunderts im Kontext der mitteldeutschen Universitäten herausbildeten. ${ }^{101}$ Leibniz und Pufendorf z. B. zählten zu ihren Mitgliedern, wie sie überhaupt durch ihr langjähriges Studium an den Universitäten Leipzig und Jena entscheidend geprägt wurden. Dass die Historiografie über dieses Thema zum Teil bis heute nichts anderes mitzuteilen hat, als das beide auf Betreiben der Orthodoxie schmählich vertrieben worden wären, ist fast schon als peinlich zu bezeichnen. Pufendorf und Leibniz, zahlreiche Namen ließen sich hinzufügen, haben auch sächsische gelehrte Schulen besucht, Pufendorf z. B. die Fürstenschule Grimma. Ganze Generationen sind von diesen Bildungseinrichtungen geprägt worden, die ohne weiteres neben den gerühmten Schuleinrichtungen Franckes in Halle genannt werden dürfen, abgesehen davon, dass es in den übrigen Ländern der Hohenzollern entsprechende Pendants an pädagogischen Anstalten nicht gegeben hat. Halles Entwicklung zu einem Aufklärungszentrum konnte sich überhaupt nur vollziehen, weil die Stadt, die in der Frühen Neuzeit übrigens offiziell als Halle in Sachsen (Hala Saxonum) geführt wurde, inmitten der so überaus reichen Kulturlandschaft Sachsens und Thüringens gelegen war. In Stendal, Havelberg oder Schwedt wäre das Experiment einer Universitätsgründung weniger erfolgreich ausgegangen. Die Entwicklung der deutschen Sprache und Literatur im 17. und 18. Jahrhundert, also im unmittelbaren Vorfeld der modernen deutschen Literaturgeschichte, hat den sächsisch-thüringischen Raum zum Zentrum und nicht die Altmark oder Pommern. Die Fortschritte der Klassischen Philologie, eine der Leitwissenschaften dieser und der kommenden Zeit, verknüpfen sich weitgehend mit Namen aus mitteldeutschen Territorien. Das alles sind nur Beispiele, die in fast alle Richtungen erweitert werden könnten.

Das geistige Leben in Deutschland ist immer bis zu einem gewissen Grade polyzentrisch geblieben, und das gilt gerade und besonders für die Zeit der Aufklärung. Preußens Anteil an jener Entwicklung ist sicher bedeutend gewesen,

100 Entsprechend kritisch urteilt Ernst Troeltsch: „Alles Geschick Harnacks kann doch die Tatsache nicht verdecken, daß es bei der Berliner Akademie überhaupt schwer ist, eine bestimmte Leistung und Stellung auszumitteln, die sie für den großen Zusammenhang des geistigen Lebens gehabt hätte. Die Idee ihres Stifters, wonach sie, Paris und London überbietend, ein Zentrum kultureller und geistiger Regeneration für Deutschland, besonders für die protestantische Vormacht Preußen, bilden sollte, ist nie zur Verwirklichung gekommen." Vgl. Troeltsch, Protestantisches Christentum (wie Anm. 20), S. 805 .

101 Vgl. Detlef Döring, Die mitteldeutschen gelehrten Kollegien des 17. und frühen 18. Jahrhunderts als Vorläufer und Vorbilder der wissenschaftlichen Akademien, in: Holger Zaunstöck/Markus Meumann (Hg.), Sozietäten, Netzwerke, Kommunikation. Neue Forschungen zur Vergesellschaftung im Jahrhundert der Aufklärung (Hallesche Beiträge zur europäischen Aufklärung 21), Tübingen 2003, S. 13-42. 
hauptsächlich allerdings erst im letzten Drittel des 18. Jahrhunderts, ${ }^{102}$ als ein unumstrittenes Mekka der geistigen Avantgarde Deutschlands kann das Land aber wohl zu keiner Zeit bezeichnet werden. Das haben kritische Zeitgenossen noch besser empfunden als die aus dem Wissen um die spätere Geschichte urteilenden Nachkommen. Ich nenne wiederum nur ein Beispiel. Als der auf Befehl des Soldatenkönigs aus Halle vertriebene Philosoph Christian Wolff fast zwei Jahrzehnte später bei dem Grafen Ernst Christoph von Manteuffel, der am Berlin/Potsdamer Hof verkehrte und mit dem Kronprinzen Friedrich befreundet war, anfragte, ob er auf das an ihn ergangene Angebot einer Rückkehr an seine frühere Wirkungsstätte eingehen solle, wird ihm abgeraten und zwar mit recht drastischen Worten: Cela est si connu en ce pays-cy, que tout de monde est persuadé, qu'on chasseroit tous les savans, et aboliroit toutes les Universitez, si l'one ne s'en promettoit du profit. Le tems, où l'on estimera les sciences par des raisons plus raisonnables, n'est pas encore arrivé, et il est très incertain, si nous vivrons assez long tems, vous et moi, pour le voir arriver. ${ }^{103}$ Es sei daher eher zu überlegen, heißt es in einem anderen Brief, ob Wolff nicht besser beraten sei, nach Leipzig zu gehen, denn die dortige Universität solle noch stärker als bisher gefördert werden, er, Manteuffel, werde dazu beitragen, sie zur blühendsten Hochschule Europas auszubauen. ${ }^{104}$ Sicher, Manteuffels Schreiben stammen aus den letzten Monaten der Regierungszeit des allen „unnützen“ Wissenschaften abholden Soldatenkönigs, dass der Graf aber von dem zu diesem Zeitpunkt absehbaren Regierungswechsel offenbar keine grundlegende Änderung erwartete, ist doch recht bezeichnend. ${ }^{105}$ Wolff ist dann trotzdem nach Halle gegangen, wirklich heimisch ist er dort jedoch nicht mehr geworden. Das hatte recht verschiedene Ursachen, darunter auch die Tatsache, dass die Aufklärungsbewegung in Preußen und in Sachsen jeweils verschiedene Entwicklungen und einen unterschiedlichen Charakter nahm. ${ }^{106}$ Freilich teilten die Sachsen mit

102 Diese Feststellung bezieht sich in der Hauptsache auf Berlin bzw. das eigentliche Brandenburg. Halle bildete selbstverständlich das gesamte 18. Jahrhundert über ein Aufklärungszentrum, wenn auch mit wechselnder Ausstrahlungskraft. Dabei ist jedoch der eben angedeutete Kontext der Hallenser Entwicklung zu berücksichtigen.

103 Ernst Christoph Manteuffel an Christian Wolff, 2. November 1739, Universitätsbibliothek Leipzig (im Folgenden: UB Leipzig), Ms 0345, Bl. 138-141. (Es ist in diesem Land bekannt, dass alle Welt davon überzeugt ist, man würde alle Gelehrten verjagen und alle Universitäten abschaffen, wenn man sich davon einen Vorteil versprechen könnte. Die Zeiten, in denen man die Wissenschaften mit mehr Vernunft schätzen wird, sind noch nicht gekommen, und es ist sehr ungewiss, ob wir lange genug leben werden, Ihr und ich, um sie kommen zu sehen).

104 Manteuffel an Wolff, 6. Juni 1739, UB Leipzig, Ms 0345, Bl. 86 f.

105 Vgl. Manteuffel an Gottsched, 20. Juli 1740 (Johann Christoph Gottsched, Briefwechsel unter Einschluß des Briefwechsels von Luise Adelgunde Victorie Gottsched, Bd. 6: Juli 1739-Juli 1740, hrsg. von Detlef Döring/Franziska Menzel/Rüdiger Otto/ Michael Schlott, Berlin/Boston 2012, S. 643). Die skeptische Sicht Manteuffels ändert sich auch in der Folgezeit nicht.

106 Was z. B. Wolff von engeren Kontakten zur Berliner Aufklärung abhielt, das war deren stark französisch geprägter Charakter, der nach dem Regierungsantritt Friedrichs II. sich noch erheblich verstärkte. Die Berliner Akademie als wichtigste Institution der 
den Brandenburgern eben nicht das epochale Erlebnis der „Weihnachtsgeschichte".

Als August der Starke zusammen mit seinem Sohn, dem Kurprinzen, im Mai 1728 Berlin besuchte, legte man in der Jungfernheide, also kurz vor dem Ziel, eine Rast ein und trank dort unter einer großen Kiefer auf die Freundschaft mit Preußen. Der Soldatenkönig markierte kurz darauf diesen Platz mit einer Holztafel mit der Inschrift: Der Koenig August bielt mit dem Sohne,/ dem Folger seines Reichs, des weißen Adlers Crone, / an diesem Orte still, sprach wie er gnädigst wolte, / daß er mit Preußen stets in Freundschaft Leben solte,/ das hat er zugesagt. Hirunter kanst du seben,/ mein Leser! welchen Tag und Jahr es ist geschehen. Gott gebe beyder Volck auch solchen Sinn und Geist, weil er uns allesamt zur Brüder=liebe weist. den 29 Maji 1728.107 Vierzig Jahre später (1769) fanden ein Kupferstecher und ein Botaniker auf einer gemeinsamen Sommerwanderung zufällig jene inzwischen deutlich beschädigte Tafel. Der Baum, an dem sie befestigt gewesen war, hatte schon einige Zeit zuvor der Axt weichen müssen. Noch einmal wird sie wiederhergestellt, aber 1790 hatte sich jede Spur von ihr verloren. Auf die Berliner Begegnung der beiden Monarchen ist auch eine Medaille geprägt worden, was der damals üblichen Praxis entsprach, für denkwürdig gehaltene Ereignisse in eherner Form der Mitwelt bekanntzumachen. Die schlichte, an abgelegener Stelle angebrachte Holztafel jedoch enthält noch eine andere Botschaft als die propagandistischen Zwecken dienende Münze. Sie bezeugt, dass die von der späteren Historiografie zum zwangsläufigen Vorgang erklärte Rivalität zwischen Preußen und Sachsen um die Dominanz in Norddeutschland so unvermeidbar vielleicht doch

Aufklärung nahm unter dem Einfluss der aus Frankreich her einwirkenden Philosophia Newtoniana alsbald eine eher kritische Position gegenüber der in Sachsen vorherrschenden Leibniz-Wolffschen Philosophie ein. Entsprechend entschieden fiel die Ablehnung der Berliner Entwicklung seitens Wolffs und der sächsischen Aufklärung aus, denn dort lauere in der Konsequenz der Atheismus: Die mit der Newtonianischen Philosophie schwanger gehen, die ich vor ein non ens halte, sind überhaupt hoch intoniret, weil sie der große Name des Newtons aufgeblasen macht, und die Freydenker meinen auch den höchsten Gipffel der Vernunfft erreicht zu baben, da sie doch Vernunfft und Misgeburten der Einbildungs=Krafft nicht unterscheiden können. Wolff an Manteuffel, 14. August 1740, UB Leipzig, Ms 0345, Bl.226f. Diese Auseinandersetzungen kulminierten schließlich im sogenannten Monadenstreit Ende der Vierzigerjahre, in dem die Akademie eine Schrift prämierte, die sich gegen ein zentrales Theorem der Philosophie Leibniz' richtete. In Reaktion darauf entfachten die sächsischen Wolffianer einen durchaus erfolgreichen und mit allen Mitteln (z. B. der der Zensur) geführten Streitschriftenkrieg, der zugleich die Überlegenheit der Leipziger gelehrten Publizistik gegenüber der Berliner unter Beweis stellte. Vgl. Johannes Bronisch, Der Mäzen der Aufklärung. Ernst Christoph von Manteuffel und das Netzwerk des Wolffianismus (Frühe Neuzeit 147), Berlin/New York 2010, S. 232-305. Der Graf Manteuffel verstand sich selbst als ausgesprochener Propagantist der Philosophie von Leibniz und Wolff.

107 Hans Eugen Pappenheim, August der Starke in der Jungfernheide. Spuren einer verschollenen Gedenkstätte des alten Spandau und Moabit, in: Zeitschrift für die Geschichte Berlins 56 (1939), S. 25-30, Abbildung der Gedenktafel auf S. 29. 
nicht gewesen ist, dass auch eine andere Option denkbar war, die beiden Staatswesen jeweils spezifische Entwicklungsmöglichkeiten eingeräumt hätte.

Denn das ist die zentrale Aussage, für die der vorliegende Beitrag plädiert: Für die Beschäftigung mit der Geschichte der Politik, Kultur, Wissenschaft, bildenden Künste u. a. im Deutschland der Frühen Neuzeit ist das Wissen um die polyzentrische Struktur des Deutschen Reiches von grundlegender Bedeutung. Es geht nicht an, Brandenburg-Preußen, das nebenbei gesagt vor Mitte des 18. Jahrhunderts eine alle anderen Territorien überragende Position noch gar nicht besessen hat, als maßstabsetzendes Modell herauszugreifen, mit dem sich alle anderen Reichsstände (meist zu ihren Ungunsten) vergleichen lassen müssen. ${ }^{108}$ Der Verlauf der Geschichte richtet sich nicht nach den Forderungen politischer Theorien oder angeblicher geschichtlicher Aufträge, sondern ist den mannigfachsten Einflüssen unterworfen. Die jeweiligen Entwicklungen nehmen so zum einen unterschiedliche Verläufe und führen zu unterschiedlichen Ergebnissen, zum anderen weisen diese Prozesse auch einen durchaus ähnlichen Charakter auf und münden in die gleichen Resultate. Der Beobachter hat das zu registrieren, aber nicht zu zensieren. Es wird aber sicher noch eine beträchtliche Zeitspanne währen, bis das tief verwurzelte borussische Geschichtsbild eine allgemein anerkannte Relativierung erfährt.

108 Schon vor fast zwanzig Jahren hat Siegfried Hoyer dafür plädiert, die „strapazierte Gegenüberstellung“ Sachsens mit dem „Territorium der Hohenzollern“ aufzugeben und den Blick auf „besser vergleichbare Fürstentümer im Reich“ zu lenken. Konkret nennt Hoyer hier Kurbayern. Vgl. Siegfried Hoyer, Wie absolut war August? in: August der Starke und seine Zeit (wie Anm. 19), S. 48-53. 